\title{
Sp1 transcription factor: A long-standing target in cancer chemotherapy
}

Carolina Vizcaíno, Sylvia Mansilla and José Portugal*

Instituto de Biología Molecular de Barcelona, CSIC, Parc Científic de Barcelona, E-08028

Barcelona, Spain

*to whom correspondence should be addressed:

Dr. José Portugal, Instituto de Biología Molecular de Barcelona, CSIC, Parc Científic de Barcelona, Baldiri Reixac, 10; E-08028 Barcelona, Spain.

Phone: +34 93403 4959, FAX: +34 93403 4979, E-mail: jpmbmc@ibmb.csic.es 


\begin{abstract}
$\mathrm{Sp} 1$ (Specificity protein 1) is a well-known member of a family of transcription factors that also includes $\mathrm{Sp} 2, \mathrm{Sp} 3$ and $\mathrm{Sp} 4$, which are implicated in an ample variety of essential biological processes and have been proven important in cell growth, differentiation, apoptosis and carcinogenesis. Sp1 activates the transcription of many cellular genes that contain putative CGrich Sp-binding sites in their promoters. Sp1 and Sp3 proteins bind to similar, if not the same, DNA tracts and compete for binding, thus they can enhance or repress gene expression. Evidences exist that the Sp-family of proteins regulates the expression of genes that play pivotal roles in cell proliferation and metastasis of various tumors. In patients with a variety of cancers, high levels of Sp1 protein are considered a negative prognostic factor. A plethora of compounds can interfere with the trans-activating activities of Sp1 and other Sp proteins on gene expression. Several pathways are involved in the down-regulation of Sp proteins by compounds with different mechanisms of action, which include not only the direct interference with the binding of Sp proteins to their putative DNA binding sites, but also promoting the degradation of Sp protein factors. Down-regulation of Sp transcription factors and Sp1-regulated genes is drug-dependent and it is determined by the cell context. The acknowledgment that several of those compounds are safe enough might accelerate their introduction into clinical usage in patients with tumors that over-express Sp1.
\end{abstract}

Keywords: Anticancer drugs; Prognosis; Sp1; Sp3; Transcription factors; Targeted therapy 


\section{Contents}

1. Introduction

2. Sp1 transcription factor and family: who are they?

3. Sp1 is involved in cell growth and tumorigenesis

4. Targeting gene expression in cancer: Sp1 and beyond

5. Knocking on the clinic's door: the Sp-family as prognostic factor and therapeutic target

6. Conclusions and perspectives

Conflict of interest statement

Acknowledgments

References 
Abbreviations: AMPK $\alpha$, AMP-activated protein kinase alpha catalytic subunit; Bcl-2, B cell/lymphoma 2; Bcl-w, member of the Bcl-2 family; Bid, BH3 interacting domain death agonist; CDK, cyclin-dependent kinase; Cdc25B, cell division cycle 25B (phosphatase); CLDN4, claudin-4; c-Met, growth factor receptor c-met oncogene; DR5, death receptor 5; DIG-MSK, demycarosyl-3D- $\beta$-D-digitoxosyl-MSK; E2F-1, E2F transcription factor 1; ERK1/2, extracellular signal-regulated kinases 1 and 2; FLIP, FLICE(caspase 8, apoptosis-related peptidase)-inhibitory protein; HB-EGF, heparin-binding EGF-like growth factor; HDAC, histone deacetylase; KAT, lysine(K)-acetyl-transferase; KCNMA1, potassium channel, calcium activated large conductance subfamily member 1; KLF6, Kruppel-like factor 6; Kras, Kirsten rat sarcoma viral oncogene homolog; miR, microRNA; NFkB, nuclear factor kappa-light-chain-enhancer of activated B cells; MSK, mithramycin SK; MSDK, mithramycin SDK; MRP-1, Multidrug resistance-associated protein 1; p15, cyclin-dependent kinase inhibitor 2B; p21, cyclin-dependent kinase inhibitor1A; PTTG-1, pituitary tumor transforming gene 1; ROS, reactive oxygen species; Smad-3, Smad family of signal transduction proteins member 3 ; TGF- $\beta$, transforming growth factor beta; VEGF, vascular endothelial growth factor; XIAP, X-linked inhibitor of apoptosis; ZBTB, zinc finger and BTB domain containing protein. 


\section{Introduction}

Many processes occurring in eukaryotic cells are regulated primarily at the transcriptional level, and the binding of protein transcription factors to specific DNA sequences is fundamental in gene regulation. The promoters of eukaryotic genes encoding for proteins bear a variety of DNA elements that are recognized by protein transcription factors, which binding to them participate in the control of gene expression (Lemon \& Tjian, 2000). At these promoters, RNA pol II forms complexes with a set of general transcription factors that bind to specific sites in DNA. These general factors are essential for basal transcription, as different from activated RNA pol II transcription. The TATA-box binding protein (TBP) is required for both TATA boxcontaining and TATA-less promoters (Tora \& Timmers, 2010) (Fig. 1). The basal transcription machinery can accurately initiate DNA transcription in vitro (Lemon \& Tjian, 2000).

Nevertheless, RNA pol II recruitment and transcription of target genes in vivo requires additional sequence-specific transcription activators and co-factors to activate transcription above basal levels (Bywater, et al., 2013; Lemon \& Tjian, 2000; Roeder, 2003) (Fig.1). Sequence-specific protein factors, such as c-myc, p53 or Sp1 bind to specific DNA sequences located in the core gene promoter or at the distant enhancer regions, and they interact with the general transcription factors and the RNA Pol II complex to enhance transcription.

Sp1 (Specificity protein 1) is one of the most well characterized transcriptional activators (Chu, 2012; Pugh \& Tjian, 1990; Suske, 1999; Wierstra, 2008). It binds to GC-rich sequences that are needed for the expression and regulation of a variety of genes (Azizkhan, et al., 1993; Kadonaga, et al., 1986; Letovsky \& Dynan, 1989; Suske, 1999). Sp1 was first recognized as a constitutive transcription activator of housekeeping genes and other TATA-less genes (Azizkhan, et al., 1993; Pugh \& Tjian, 1990; Suske, 1999), but nowadays many other roles have been described, including its implication in cell growth control and tumorigenesis (Li \& Davie, 2010). $\mathrm{Sp} 1$ is a member of a family of transcription factors, which also includes Sp2, Sp3 and Sp4 
(Suske, 1999; Wierstra, 2008). The Sp-family of transcription factors plays central roles in cell cycle regulation (Deniaud, et al., 2009; Li \& Davie, 2010; Suske, 1999) and during development (Gilmour, et al., 2014; Marin, et al., 1997; Zhao \& Meng, 2005). Although Sp1 and Sp3 can bind to the same consensus binding sites, both their DNA-binding properties and regulatory functions are different, depending on the promoter context and cellular background (Fandos, et al., 1999; López-Soto, et al., 2006; Majello, et al., 1995; Safe \& Abdelrahim, 2005; Suske, 1999; Yu, et al., 2003) and Sp1 activity is regulated by post-translational modifications and by interactions with other protein factors.

Sp1 (Specificity protein 1) and other members of its family are often over-expressed in several human cancers, where $\mathrm{Sp} 1$ is, in general, considered a negative prognostic factor (Guan, et al., 2012; Safe \& Abdelrahim, 2005; Sankpal, et al., 2012; Wierstra, 2008). Sp1 target genes are mainly involved in cell proliferation and oncogenesis (Safe \& Abdelrahim, 2005; Wierstra, 2008), and Sp1-responsive genes are among those belonging to the hallmarks of cancer, which comprise biological capabilities acquired during the multistep development of human tumors (Beishline \& Azizkhan-Clifford, 2015; Hanahan \& Weinberg, 2011).

Binding of transcription factors to specific DNA tracts in gene promoters is a key step towards transcriptional activation or repression. Therefore, DNA-binding drugs are considered potential agents aimed at inhibiting unpaired transcription that could prevail in several pathologies, including cancer (Gniazdowski, et al., 2005; Hurley, 2002; Portugal, et al., 2011). It is worth noting that the foremost mechanism of action of many of the first-line cytotoxic agents already approved by for clinical usage, including DNA-alkylating agents and the anthracyclines, is the ability to inhibit transcription (Gniazdowski, et al., 2005; Portugal, et al., 2011). However, there are only a few examples of molecules developed to target the dysregulation of transcription, and despite challenges involved in making molecules aimed at targeting transcription factors, there are grounds for considering that this approach is a highly promising strategy in the development of cancer treatments (Frank, 2009; Yan \& Higgins, 2013). The number of 
transcription factors that modulate transcription is impressively large $(\sim 2500)$, and binding events can exceed the number of known direct gene targets (Bywater, et al., 2013; MacQuarrie, et al., 2011). The prognostic significance of Sp1 transcription factor in cancer development, as well as the pro-oncogenic activities of the Sp-family of transcription factors, makes these protein factors an adequate model for examining the effects of "anti-transcriptional" therapies and for stimulating the interest in the development of novel drugs that may take advantage of their effects on gene expression (Mansilla \& Portugal, 2008; Safe, et al., 2014).

There are approaches other than interfering Sp transcription factors through DNA-drug interactions to target the down-regulation of Sp-activated genes. Several compounds exist that can repress $\mathrm{Sp} 1, \mathrm{Sp} 3$ and $\mathrm{Sp} 4$ gene expression through induction of transcriptional repressors that competitively bind and displace member of the Sp-family of transcription factors from its GCrich putative binding sites in promoters. Induction of those repressors can be attained through the down-regulation of certain micro-RNAs, a mechanism that is linked to drug-induced production of reactive oxygen species (ROS) (Chintharlapalli, et al., 2007; Jutooru, et al., 2010b; Jutooru, et al., 2014; Mertens-Talcott, et al., 2007). Moreover, down-regulation of Sp proteins by caspases or by the activation of the proteasome has been reported (Abdelrahim \& Safe, 2005; Chadalapaka, et al., 2008; Chintharlapalli, et al., 2011b; Pathi, et al., 2012; Piedrafita \& Pfahl, 1997). All these aspects are extensively discussed in the following paragraphs together with the prognostic value of knowing the Sp-levels in experimental cancer and in patients.

\section{Sp1 transcription factor and family: who are they?}

$\mathrm{Sp} 1$ is a ubiquitous transcription factor that recognizes the CG-rich consensus sequence 5'(G/T)GGGCGG(G/A)(G/A)(C/T)-3', interacting with DNA through three C2H2-type zinc fingers located at its C-terminal domain (Suske, 1999; Wierstra, 2008). Sp1 is not the only protein acting through the 'Sp1-binding sites' but is the first identified member of a family that also encompasses Sp2, Sp3 and Sp4 proteins. All four Sp-family members have similar domain structures (Suske, 1999). However, Sp2, which has a different consensus-binding site, localizes to 
sub-nuclear foci associated with the nuclear matrix, and it can activate or sometimes repress expression from different promoters (Moorefield, et al., 2006). Sp2 is essential for early mouse development and for the proliferation of mouse embryonic fibroblasts in culture (Terrados, et al., 2012). Both Sp1 and Sp3 are ubiquitous (Li, et al., 2004) while Sp4 shows a more tissuerestricted expression pattern (Suske, 1999), being rather abundant in neuronal cells (Hagen, et al., 1992). In general, Sp1 and Sp3 can act as positive or negative regulators of gene expression (Li \& Davie, 2010; Suske, 1999). Studies using knockout mouse models have demonstrated that Sp1 is essential in early embryonic development, but dispensable for cell growth and differentiation (Marin, et al., 1997), while mice lacking Sp3 showed impaired bone formation (Göllner, et al., 2001). Furthermore, Sp1/Sp3 compound heterozygous mice are not viable (Krüger, et al., 2007).

Although $\mathrm{Sp} 1$ is sometimes viewed as a constitutive transcriptional activator acting as a basal factor for TATA-less promoters, it is also implicated in gene trans-activation in response to a variety of cellular signals (Black, et al., 1999; Safe \& Abdelrahim, 2005; Wierstra, 2008) (Fig. 1). It can trans-activate via a single binding site, or synergistically with itself via two or more Sp1binding sites without cooperative binding to DNA (Courey, et al., 1989; Pugh \& Tjian, 1990). Sp1-dependent transcription is regulated in response to a variety of signals (Wierstra, 2008). The number of Sp1 molecules is estimated to be $\sim 5000-10000$ in a mammalian cell (Letovsky \& Dynan, 1989), but in some cell lines there is evidence of changes in Sp1 levels through the cell cycle (Li, et al., 2004), and it has been shown that the relative Sp1/Sp3 protein levels can regulate gene expression (Suske, 1999). An interesting feature of Sp3 is that it exists not only as the long isoform, but also as two short isoforms that arise from differential translational initiation. The short Sp3 isoforms may be responsible for Sp3-mediated transcriptional repression (Kennett, et al., 1997). Sp3 has a dual role as inductor of apoptosis and as a marker of tumor aggressiveness, which appears to coincide with accumulation of its full-length form (Essafi-Benkhadir, et al., 2009). Sp1 and Sp3 can interact with and recruit the transcription initiation complex, histone modifying enzymes and chromatin remodeling complexes. This suggests that $\mathrm{Sp} 1$ and $\mathrm{Sp} 3$ are 
important in the remodeling of chromatin and the regulation of gene expression (Li \& Davie, 2010). Sp3 represses the Sp1-mediated trans-activation of promoters bearing two or more Sp1binding sites, yet it does not affect the Sp1-mediated trans-activation of promoters with only one Sp1 site, and Sp3 cannot trans-activate synergistically through two or more Sp1-binding sites (Yu, et al., 2003).

Sp1 can be modified by phosphorylation, sumoylation, acetylation and glycosylation, while Sp3 modifications include phosphorylation, sumoylation, and acetylation. Phosphorylated Sp1 and $\mathrm{Sp} 3$ have been reported to up- or down-regulate gene transcription (Chu, 2012; $\mathrm{Li}$, et al., 2004), and altered levels of phosphorylation appear to result in changes in the DNA-binding activities (Chu, 2012). For example, Cyclin A-CDK mediated phosphorylation increases the DNA-binding activity of Sp1 (Fojas-de-Borja, et al., 2001). Sp1 and Sp3 can recruit and form complexes with other factors (Li, et al., 2004; Wierstra, 2008). Many transcription factors interact with Sp1 either directly or indirectly. A comprehensive compilation of these interactions has been published elsewhere (Wierstra, 2008).

Sp3 can be acetylated by p300, a histone acetyl transferase (Ammanamanchi, et al., 2003), and acetylated Sp3 has been considered a transcriptional activator (Ammanamanchi, et al., 2003). Also, p300 binds to Sp1 at its DNA-binding domain. When Sp1 is bound to DNA, it cannot be acetylated, and the treatment with HDAC inhibitors, as well as induction of oxidative stress, can result in Sp1 acetylation in cells, which seems to enhance Sp1 binding to DNA (Li, et al., 2004). O-linked glycosylation of Sp1 may stimulate or repress transcription (Wierstra, 2008), and it can interfere with the access of Sp1 to modifying enzymes like kinases. Increase in phosphorylation and glycosylation lead to Sp translocation into nuclei (Black, et al., 1999). Sumoylation of $\mathrm{Sp} 1 / \mathrm{Sp} 3$ can be implicated in several regulatory functions such as subcellular compartmentalization and protein stability (Li, et al., 2004). Sumoylation of Sp3 occurs at a unique lysine within the inhibitory domain, what can silence, or significantly decrease, Sp3 
activity (Li, et al., 2004), while sumoylation of Sp1 would enhance its degradation (Wang, et al., 2008b).

Remodeling of highly compacted chromatin is needed to make DNA sequences available for transcription factors and RNA polymerases. The steady state of acetylation of chromatin regions is determined by the relative activities of KATs and HDACs. KATs and HDACs catalyze acetylation and deacetylation of the core histones, thus histones associated with regulatory and coding regions of transcribed genes can be acetylated and deacetylated. A mode for gene activation by $\mathrm{Sp} 1$ arises from the disruption of the direct interaction between $\mathrm{Sp} 1$ and HDAC1 (Doetzlhofer, et al., 1999; Wierstra, 2008), which recruits Sp1 to its target genes. Sp1 is in this way implicated in the HDAC-dependent repression of $\mathrm{p} 21^{\mathrm{WAF} 1}$ (Doetzlhofer, et al., 1999). E2F-1 and HDAC1 bind to the same domain of Sp1, so they compete for binding to it (Doetzlhofer, et al., 1999). Therefore, E2F-1 can displace HDAC1 from Sp1 and release Sp1 target genes from their repression by HDAC1. Besides, HDAC4 represses p2 ${ }^{\text {WAF1 }}$ expression in human cancer cells through an Sp1-dependent, p53-independent mechanism (Mottet, et al., 2009).

\section{Sp1 is involved in cell growth and tumorigenesis}

Sp1 not only regulates the expression of multiple genes, but also the $S p 1$ gene itself (Nicolás, et al., 2003; Tapias, et al., 2008). Abnormal Sp1 protein levels have been observed in several cancers (Safe \& Abdelrahim, 2005; Safe, et al., 2014; Sankpal, et al., 2012; Wang, et al., 2003). $\mathrm{Sp} 1$ is over-expressed in a host of human cancers, in which $\mathrm{Sp} 1$ levels correlate with tumor stage and poor prognosis (Guan, et al., 2012; Safe \& Abdelrahim, 2005; Sankpal, et al., 2012; Wang, et al., 2003), while the inhibition or knocking-down of Sp1 to the normal cellular level usually decreases tumor formation, growth and metastasis (Jiang, et al., 2004; Lou, et al., 2005; Previdi, et al., 2010; Yuan, et al., 2007). Sp1 plays a major role in the regulation of the expression of the vascular endothelial growth factor (VEGF) in a variety of tumors, and several different strategies have been designed to target VEGF signal transduction, including Sp1 down-regulation (Ishibashi, et al., 2000; Jia, et al., 2007; Safe, et al., 2014; Wang, et al., 2003). The expression of 
the $\mathrm{Sp} 1$ protein is high in a large percentage of breast carcinomas, while only one in five benign breast lesions express detectable levels of Sp1 (Zannetti, et al., 2000). Sp1 and Sp3 bind to the same sites on the oncogene $c$-myc promoter, upstream to both the $\mathrm{P} 1$ and $\mathrm{P} 2$ initiation sites (Majello, et al., 1995). Co-transfection experiments indicate that $\mathrm{Sp} 1$ trans-activates the $c-m y c$ promoter, while Sp3 does not (Majello, et al., 1995). A genome-wide analysis of chromatin occupancy by p53 and a parallel analysis of gene expression have identified $\mathrm{Sp} 1$ as one of the p53 modulators that confer specificity to p53-mediated transcriptional response upon induction of tumor cell apoptosis (Nikulenkov, et al., 2012). Although Sp1 could be indispensable for the proapoptotic transcriptional repression by $\mathrm{p} 53$, it is not for the induction of pro-apoptotic genes ( $\mathrm{Li}$, et al., 2014a).

Sp1 over-expression induces apoptosis, whereas a dominant-negative form of Sp1 suppresses it (Deniaud, et al., 2006; Wierstra, 2008). The binding of over-expressed Sp1 can inhibit the cell cycle progression that precedes apoptosis, together with a transcriptional response in genes that contain Sp1 binding sites in their promoters (Deniaud, et al., 2009). The transcriptional response induced by over-expressed Sp1 involves both direct Sp1-driven transcription and other indirect mechanisms (Deniaud, et al., 2009). Expression of Sp1, Sp3, and Sp4 in cancer cell lines has been linked to the microRNA-dependent regulation of transcriptional repressors such as ZBTB10, ZBTB4 and ZBTB34, which do not bear trans-activation domains. These repressors can competitively bind to GC-rich tracts in promoters and displace Sp proteins to decrease transcription (Jutooru, et al., 2014; Kim, et al., 2012; Mertens-Talcott, et al., 2007; Noratto, et al., 2013). Several microRNA precursors found in humans can repress ZBTB4, ZBTB10 and ZBTB34. The expression of ZBTB10 is repressed by microRNA 27a (miR-27a) (Mertens-Talcott, et al., 2007) and ZBTB4 is repressed by miR-20a and miR-17-5-p (part of the miR-17-92 cluster) and other related molecules (Kim, et al., 2012). ROS decrease the expression of miR-27a/miR20a:miR-17-5p and induce miR-regulated ZBTB10, ZBTB4 and ZBTB34 transcriptional 
repressors, and subsequent down-regulation of Sp proteins (Jutooru, et al., 2014; Mertens-Talcott, et al., 2007; Noratto, et al., 2013).

Among the Sp1-target genes there are key players in cell proliferation and oncogenesis, including prominent oncogenes and tumor suppressors (Wierstra, 2008). In fact, Sp1-target genes belong to the hallmarks of cancer: self-sufficiency in growth signals, insensitivity to anti-growth signals, evasion of apoptosis, limitless replicative potential, sustained angiogenesis, tissue invasion and metastasis, reprogramming of energy metabolism, and evading immune destruction (Beishline \& Azizkhan-Clifford, 2015; Hanahan \& Weinberg, 2011; Wierstra, 2008).

Sp1 activates the transcription of genes encoding for cyclin kinases such as D-type cyclins, cyclin E, Cdk2, as well as the $E 2 F-1$ and $c-m y c$ genes, which participate actively in the progression through G1-phase and entry into S-phase. Therefore, Sp1 could contribute to G1/Stransition as the entry into S-phase is induced together by cyclin $\mathrm{D} / \mathrm{Cdk} 4$ and cyclin $\mathrm{E} / \mathrm{Cdk} 2$ (Sherr \& Roberts, 1999). E2F-1 and c-Myc are transcription factors that induce quiescent cells to entry S-phase (Bretones, et al., 2015; Stevens, et al., 2003). Hence, Sp1 over-expression increases the percentage of cells in S-phase, whereas knockdown of Sp1 decreases the number of cells in Sphase (Abdelrahim, et al., 2004; Safe \& Abdelrahim, 2005). Sp1 associates with the retinoblastoma protein $(\mathrm{Rb})$ to activate the dihydrofolate reductase promoter (Noé, et al., 1998). Sp1 also activates the transcription of genes encoding for many cyclin-dependent inhibitors (Wierstra, 2008). Sp1 could contribute to cell cycle arrest, as p53 synergizes with Sp1 to transactivate the $p 21^{W A F 1}$ promoter (Koutsodontis \& Kardassis, 2004; Koutsodontis, et al., 2002), and Smad2/3/4 synergizes with $\mathrm{Sp} 1$ in trans-activation of the $p 15^{I N K 4 B}$ promoter in response to the growth-inhibitory cytokine TGF- $\beta$ (Feng, et al., 2000). Interestingly, Sp1 is phosphorylated specifically in mid-late G1-phase (Black, et al., 1999). Pin1, a peptidyl-prolyl isomerase, which is highly expressed in several cancers, including prostate, breast, lung and colon cancers, mediates Sp1 phosphorylation by CDK1 and increases Sp1 stability and decreases its DNA-binding activity during mitosis (Yang, et al., 2014a). Besides, Sp1 and Sp3 levels are kept constant during 
mitosis, which would indicate a significant recovery of the pre-existing levels in newly formed nuclei (He \& Davie, 2006). During vascular injury and inflammation TGF- $\beta$ is induced through an interaction between Sp1 and KLF6, whereas it increases endoglin transcription through a Smad 3-Sp1 interaction (Botella, et al., 2001). Sp1 is also a key factor in maintaining basal mitofusin-2 (Mfn2) transcription in vascular smooth muscle cells. Because of the antiproliferative actions of Mfn2, Sp1-induced Mfn2 transcription is considered a mechanism for the prevention of proliferation of the vascular smooth muscle cells (Sorianello, et al., 2012).

\section{Targeting gene expression in cancer: Sp1 and beyond}

Figures 2 and 3 display the chemical structures of several compounds that target $\mathrm{Sp}$ transcription factors. Some of those molecules alter transcription in human cancer cells in culture, as well as in tumor xenografts in mice, through the interference with DNA-drug interactions —a defining feature that can prevail during clinical treatment of cancer (Hurley, 2002; Portugal, et al., 2011) - , together with other molecules that interfere with the Sp-family of proteins through other mechanisms that include, among others, the generation of reactive oxygen species and the activation of the proteasome (Safe, et al., 2014). We shall discuss these mechanisms in the following paragraphs.

\subsection{DNA-binding drugs and the role of Sp1/Sp3 in gene transcription}

Several compounds displaying sequence selectivity in their binding to DNA can exhibit differential effects on the interactions between DNA and DNA-binding proteins, which includes the members of the Sp-family (Chiang, et al., 1998; Gniazdowski, et al., 2005; Hurley, 2002; Lee, et al., 2009; Mansilla \& Portugal, 2008; Minuzzo, et al., 2000; Portugal, et al., 2011; Snyder, et al., 1991). The clinical success as antitumor drugs of a number of DNA-binding chemotherapeutic agents is ascribed, at least in part, to their capacity for inhibiting transcription (Gniazdowski, et al., 2005; Hurley, 2002; Portugal, et al., 2011).

Given that a primary mechanism of Sp-dependent transcription in cancer involves initial binding to its putative GC-rich tracts in promoters, followed by subsequent interactions with the 
basal transcription machinery to activate transcription (Fig. 1), it follows a great interest in interfering gene expression by acting on Sp1 activity. Sp1 was not only the first transcription factor identified and characterized (Kadonaga, et al., 1986; Pugh \& Tjian, 1990), but its binding to gene promoters is also the target for a plethora of DNA-binding compounds that show preferential binding to GC-rich regions in DNA (Gniazdowski, et al., 2005; Hurley, 2002; Portugal, et al., 2011).

Among the molecules that can prevent the binding of Sp1 to its putative binding sites in the gene promoters are mithramycin A (Gniazdowski, et al., 2005; Snyder, et al., 1991) and several of its analogs obtained by combinatorial biosynthesis (Albertini, et al., 2006; Bataller, et al., 2008; Fernández-Guizán, et al., 2014; Malek, et al., 2012; Previdi, et al., 2010; Vizcaíno, et al., 2012; Vizcaíno, et al., 2014) (Fig. 3). Mithramycin A has been used in the treatment of Paget's disease and advanced testicular carcinoma, but it showed numerous toxic side effects that have limited its clinical use (King \& Perry, 2001). However, mithramycin A has gained renewed attention as therapeutic agents in cancer- and non-cancer-related diseases (Gao, et al., 2011; Grohar \& Helman, 2013; Hagiwara, et al., 2009; Previdi, et al., 2010; Sleiman, et al., 2011). The novel mithramycin analogs encompass improved pharmacological properties compared to the parental mithramycin A (Núñez, et al., 2012; Previdi, et al., 2010), while they also bind to DNA and alter Sp-DNA interactions (Albertini, et al., 2006; Barceló, et al., 2010; Barceló, et al., 2007; Fernández-Guizán, et al., 2014). The effects of the new analogs on Sp1-transactivated gene expression, together with their lower toxicity, opens new perspectives for their clinical use.

Anthracyclines, which are among the most effective anticancer treatments ever developed (Minotti, et al., 2004), bind tightly to DNA at CG-rich DNA sequences (Frederick, et al., 1990). Among them, the binding of daunorubicin and doxorubicin (Fig. 2) to DNA has been widely characterized (Chaires, et al., 1990; Frederick, et al., 1990), and the information obtained has been used for the rational design of new bisanthracyclines targeted toward DNA (Chaires, et al., 1997; Leng, et al., 1998; Portugal, et al., 2001; Priebe, et al., 2001). Daunorubicin and the bis- 
intercalating anthracycline WP631 (Fig. 2) —which binds to DNA with higher affinity (Chaires, et al., 1997) — inhibit Sp1-DNA interactions and gene transcription (Mansilla \& Portugal, 2008; Mansilla, et al., 2006b; Martín, et al., 1999). Daunorubicin and doxorubicin can inhibit the Sp1activated transcription, yet WP631 is more efficient at inhibiting transcription initiation from promoters containing an Sp1-binding site, and it is a potent inhibitor of Sp1-activated transcription both in vitro and in human cell lines (Mansilla \& Portugal, 2008; Mansilla, et al., 2004).

In the presence of wild-type p53, doxorubicin activates the promoter of $C d c 25 B$ (this gene encodes a phosphatase that activates the cyclin dependent kinase cdc 2 required for entering mitosis) by preventing the binding of Sp1 and increasing the binding of NF-Y to the promoter, thus halting p53 from down-regulating gene expression (Dalvai, et al., 2013). The control of the expression of the anti-apoptotic survivin has significant consequences for cancer therapeutics. Sp1 and Sp3 regulate its gene transcription (Mobahat, et al., 2014; Xu, et al., 2007). Hedamycin, a monofunctional DNA alkylating agent, down-regulates survivin expression. This drug abrogates the binding of Sp-1 or Sp1-like proteins to the putative binding element in its promoter $(\mathrm{Wu}$, et al., 2005). Down-regulation of survivin transcription by hedamycin would modulate the viability of some cancer cells (Wu, et al., 2005). Drug-mediated repression of survivin is also attained by doxorubicin in experiments showing that $\mathrm{Sp} 1$ transcription factor acts as a platform for the recruitment of some transcriptional repressors (Estève, et al., 2007).

Elsamicin A, a DNA intercalator, modulates in vitro DNA-protein interactions in the P1 and P2 c-myc promoters (Vaquero \& Portugal, 1998). The effect of elsamicin A on Sp1 binding is dose-dependent, and it acts as a strong inhibitor of the transcription from the P1 start site, but not from the P2 (Vaquero \& Portugal, 1998). Actinomycin D (Fig. 2), a DNA intercalator in clinical usage, also inhibits the transcription from the $\mathrm{P} 1 c-m y c$ promoter in a concentration-dependent manner. Both elsamicin A and actinomycin D can inhibit the interaction between Sp1 and its putative binding sites in $c$-myc promoters (Vaquero \& Portugal, 1998). Actinomycin D has also 
been used to prove that the Sp1 transcription factor contributes to the tumor necrosis factorinduced expression of an angiogenic factor in colon carcinoma cells (Zhu, et al., 2002).

High throughput profiling of gene expression by DNA microarrays allows us to analyze the transcriptional regulation of thousands of genes. For example, in pancreatic cancer a plethora of differentially expressed genes have been identified as being involved in its progression and in the regulation of cell cycle and apoptosis (Wang, et al., 2014), providing a comprehensive recognition of genes and pathways which may be involved in the progression of pancreatic cancer (Wang, et al., 2014), while it renders data on some drugs that may be used to treat it. Sp1 has been predicted to be the major regulator of genes involved in the progression of pancreatic cancer (Wang, et al., 2014). Besides, genome-wide studies have shown that mithramycin A and several of its analogs (Fig. 3), which are both more active and less toxic, inhibit the transcription of several genes, and they also alter multiple downstream pathways that are critical in tumor development (Albertini, et al., 2006; Malek, et al., 2012; Previdi, et al., 2010; Vizcaíno, et al., 2014). In those analyses, changes are observed, mainly down-regulation, in the expression of genes that can be activated by $\mathrm{Sp}$ transcription factors. Genes showing altered expression after treatments are involved in a variety of cell processes including transcription regulation and tumor development, which can commit cells to dying (Malek, et al., 2012; Previdi, et al., 2010; Vizcaíno, et al., 2014). Some of those genes are linked to cell proliferation and poor prognosis in ovarian cancer (Crijns, et al., 2009). Sp1 regulates most of the genes that are down-regulated by the mithramycin analogs in ovarian cell lines (Previdi, et al., 2010; Vizcaíno, et al., 2014).

In A2780 human ovarian carcinoma cells, the novel mithramycin analog DIG-MSK (Fig. 3) down-regulates genes involved in several biological processes and molecular functions related to transcription and its cellular regulation (Fig. 4), including transcription factor activity (Vizcaíno, et al., 2014). Chromatin immunoprecipitation, has substantiated that binding of Sp1 to the promoters of the down-regulated genes is highly abolished by DIG-MSK (Vizcaíno, et al., 2014). A superior effect is observed on KCNMA1 (Vizcaíno, et al., 2014), a gene associated with high 
cancer cell proliferation (Oeggerli, et al., 2012). A direct effect is also observed on XIAP, in keeping with that the parental analog mithramycin A sensitizes cancer cells to TRAIL-mediated apoptosis by down-regulation of XIAP through Sp1 sites in its promoter (Lee, et al., 2006). In vitro and in vivo down-regulation of XIAP expression in ovarian cancer cells has been linked to cell death (Shaw, et al., 2008; Vizcaíno, et al., 2014).

Transcription factor decoys based on oligonucleotides that mimic the DNA-binding sites for transcription factors can prevent Sp1 activity. GC-rich double-strand oligonucleotides recognize and bind to members of the Sp-family, decreasing Sp-regulated transactivation when delivered into cells (Ishibashi, et al., 2000; Lee, et al., 2013). However, decoy molecules have low biological availability and limited cellular uptake.

\subsection{Drugs and natural molecules which alter Sp protein factors and their activities by varied}

\section{mechanisms}

There are other mechanisms of Sp down-regulation that do not depend, at least directly, on drug-DNA interactions, but they can be mediated by increased ubiquitination of Sp1, Sp3 and $\mathrm{Sp} 4$, and induced activation of the proteasome, or take place via the production of ROS, which, among other effects, can down-regulate the Sp transcription factors. For a subset of compounds, repression of $\mathrm{Sp}$-factors is linked to ROS-induced activation of ZBTB4 and ZBTB10 proteins, which, as described above, can competitively displace Sp factors from binding to CG-rich sites to decrease transcription (Jutooru, et al., 2014; Mertens-Talcott, et al., 2007; Safe, et al., 2014).

Several non-steroidal anti-inflammatory drugs, including tolfenamic acid (Fig. 2), which is considered a promising antitumor agent (Abdelrahim, et al., 2006), can increase the ubiquitination of Sp1, Sp3 and Sp4, and their proteasome-dependent degradation (Abdelrahim \& Safe, 2005). Besides, aspirin induces caspase-dependent cleavage of Sp1, Sp3 and Sp4 protein factors, a cell's response that has been related to sequestration of zinc ions (Pathi, et al., 2012). Metformin, a firstline drug of choice for the treatment of type 2 diabetes, is also a cancer-preventive molecule that targets Sp1, Sp3 and Sp4 in pancreatic cancer cells (Nair, et al., 2013; Nair, et al., 2014). 
In recent years, there have been considerable efforts to search for naturally occurring substances, including several 'nutraceuticals', for fighting cancer (Gullett, et al., 2010). Many components of medicinal or dietary plants have been identified to possess potential chemopreventive properties. Several of these molecules can affect the levels of Sp transcription factors through diverse molecular mechanisms (Safe, et al., 2014). Curcumin (diferuloylmethane), a naturally occurring flavinoid derived from the rhizome of Curcuma longa (Fig. 2), is a compound extensively investigated as an anticancer drug, which can induce proteasomedependent down-regulation of Sp1, Sp3, and Sp4 in bladder cancer cells (Chadalapaka, et al., 2008). In pancreatic cells, the reduction in the expression of the Sp-family of proteins by curcumin depends on the rise of ROS and a decrease in the mitochondrial membrane potential (Jutooru, et al., 2010b). In SW-480 human colorectal adenocarcinoma cells, curcumin also downregulates $\mathrm{Sp} 1, \mathrm{Sp} 3$, and $\mathrm{Sp} 4$ as well as some Sp-regulated genes. In these cells, the induction of ROS by curcumin would suppress the expression of microRNA-27a (miR-27a) followed by induction of the transcriptional repressor ZBTB10, which, in turn, down-regulates Sp1, Sp3, and Sp4 (Noratto, et al., 2013).

Among the anticancer drugs that can induce ROS, arsenic trioxide (Fig. 2), the methyl ester of 2-cyano-3,12-dioxo-oleana-1,9-dien-28-oic acid (CDDO-Me) and betulinic acid (a naturally occurring pentacyclic triterpenoid) down-regulate $\mathrm{Sp} 1, \mathrm{Sp} 3$, and $\mathrm{Sp} 4$ transcription factors and Spregulated genes (Chintharlapalli, et al., 2011b; Chintharlapalli, et al., 2007; Jutooru, et al., 2010a; Jutooru, et al., 2010c; Jutooru, et al., 2014; Safe, et al., 2014). Arsenic trioxide appears to modulate several pathways in cancer cells leading to increased apoptosis, inhibition of cell proliferation and angiogenesis in cancer cell lines (Jutooru, et al., 2010c; Safe, et al., 2014), and it has been indicated that arsenic trioxide suppresses transcription of the human telomerase reverse transcriptase ( $h T E R T)$ gene through the regulation of multiple transcription factors, including Sp1 (Zhang, et al., 2015). 
There are several natural products, other than curcumin and betulinic acid mentioned above, which also appear to affect Sp factors, such as some cannabinoids that can decrease the expression of the Sp-family of transcription factors (Sreevalsan \& Safe, 2013) or resveratrol (3,5,4'-trihydroxy-trans-stilbene), a 'nutraceutical' compound obtained from grapes and other fruits, which represses cell growth and can inhibit Sp1 directly (Lee, et al., 2012).

\section{Knocking on the clinic's door: the Sp-family as prognostic factor and therapeutic target}

Abnormal Sp1 protein levels are observed in several cancers and they are highly correlated with the stage of disease and poor prognosis (Safe, et al., 2014; Yao, et al., 2004). When Sp1 is knocked-down to the normal cellular levels, tumor formation can be reduced (Li, et al., 2014a; Lou, et al., 2005). Most current studies have focused on Sp1 expression, although dysregulation of Sp3 has also been described in various cancers (Li \& Davie, 2010; Safe, et al., 2014; Sankpal, et al., 2012). Almost every study shows that $\mathrm{Sp} 1$ is a negative prognostic factor in a large selection of patients having different cancers. In the following paragraphs, we shall review the information gathered from studies in cells, mice bearing human tumor xenografts and in patients, which might be of interest in the development of "Sp-based" therapies.

\subsection{Sp transcription factors in gastric cancer}

Expression of Sp1 transcription factor is a significant predictor of survival in human gastric cancer (Wang, et al., 2003), which is one major malignancy worldwide (Siegel, et al., 2015; Torre, et al., 2015). Strong Sp1 expression has been detected in neoplastic gastric cells, whereas no or very weak Sp1 expression is detected in stromal cells and normal glandular cells surrounding tumors (Wang, et al., 2003). Normal and malignant gastric tissues display unique Sp1 expression patterns (Wang, et al., 2003; Zhang, et al., 2005). Survival of patients after surgical tumor resection seems to correlate with whether those tumors were classified by immunohistochemistry as having negative, weak, and strong Sp1 expression, respectively (Wang, et al., 2003). High levels of Sp1 expression, together with increased VEGF expression, which is trans-activated by Sp1, results in poor survival in patients with resected gastric cancer (Yao, et al., 
2004). Besides, Bcl-w-induced Sp1 activation has been suggested as a putative marker for aggressiveness in gastric tumors (Lee, et al., 2014). In orthotopic nude mouse models, treatment with bevacizumab, a neutralizing antibody against VEGF, abrogates gastric cancer growth, while the combined treatment with bevacizumab and mithramycin A produces a synergistic tumor suppression, which is consistent with suppression of Sp1 expression by mithramycin A (Wang, et al., 2008a). Moreover, in mice the occurrence of gastric tumor growth and of metastasis in the liver was lower upon co-treatments with bevacizumab plus mithramycin A (Wang, et al., 2008a).

\subsection{Sp transcription factors in pancreatic cancer}

Pancreatic cancer is a rather aggressive malignancy with poor prognosis (Siegel, et al., 2015; Torre, et al., 2015). Due to the aggressive nature of this malignancy, there is a serious concern for identifying effective targets, and adopting novel strategies for therapy (Sankpal, et al., 2012). Sp1 levels are up-regulated in pancreatic cancer cell lines and in surgically resected human pancreatic adenocarcinoma, and over-expression of $\mathrm{Sp} 1$ in tumor tissues has been associated with aggressive disease (Abdelrahim, et al., 2004; Jiang, et al., 2008; Sankpal, et al., 2012). The analysis of Sp1 expression in pancreatic adenocarcinoma, evaluated by immunohistochemical staining, indicated that $\mathrm{Sp} 1$ protein was aberrantly over-expressed in a subset of patients with primary pancreatic adenocarcinoma (Sankpal, et al., 2012). All these "Sp1-overexpressing tumors" developed metastasis, whereas none of the primary tumors without lymph node metastasis showed Sp1 overexpression (Sankpal, et al., 2012). Hence, Sp1 over-expression is associated with higher stage, higher grade, and lymph node metastasis (Jiang, et al., 2008). In pancreatic cancer, Sp1 also induces angiogenesis by regulating the expression of $V E G F$ and its receptors (Abdelrahim, et al., 2004). In summary, Sp1 can identify pancreatic ductal adenocarcinomas with aggressive clinical behavior, and this might be used for initial diagnosis of pancreatic adenocarcinoma (Jiang, et al., 2008).

In nude mice, bevacizumab suppresses angiogenesis by inhibiting VEGF, and reduces the growth of human pancreatic xenografts (Jia, et al., 2007). The treatment with bevacizumab up- 
regulates the expression of $\mathrm{Sp} 1$ and its downstream target genes, including $V E G F$. It seems that treatment with bevacizumab would block VEGF function while activating the pathway of its expression through a positive feedback (Jia, et al., 2007). Mithramycin A has been used to suppress the induced Sp1 expression in tumors growing in nude mice (Jia, et al., 2007). Combined treatments with bevacizumab plus mithramycin result in synergistic tumor suppression effects, consistent with suppression of the Sp1 expression seemingly produced by the DNAbinding drug (Jia, et al., 2007). It might be concluded that alteration of Sp1 signaling in antiangiogenic therapy has significant and potential clinical implications for the treatment of pancreatic cancer.

Tolfenamic acid (Fig. 2) is an anti-inflammatory agent in phase I clinical trials (Sankpal, et al., 2013). In pancreatic cancer cells, tolfenamic acid inhibits VEGF expression, an effect that has been associated with the down-regulation of Sp-dependent trans-activation of the VEGF promoter (Abdelrahim, et al., 2006). In a mouse model of pancreatic cancer, this compound induces the proteasome degradation of Sp1, Sp3, and Sp4, together with a decrease in tumor growth (Abdelrahim, et al., 2006). Combined treatments of pancreatic cancer cells with mithramycin A and tolfenamic acid promote Sp1 degradation, showing synergistic antitumor activity (Jia, et al., 2010).

Combining betulinic acid and mithramycin A — both exhibit potent antitumor activity and effects on Sp1 through different mechanisms - has synergistic antitumor activity in xenografts of human pancreatic cancer, including inhibitory effects on cell proliferation, invasion, and angiogenesis (Gao, et al., 2011). Moreover, treatment with betulinic acid or mithramycin A has little effect on the recruitment of Sp1 to its own promoter and to the VEGF gene promoter, while co-treatments significantly decrease the Sp1 recruitment to these promoters in pancreatic cell lines (Gao, et al., 2011).

Metformin activity against pancreatic cancer occurs, in part, through the down-regulation of Sp transcription factors and Sp-regulated genes, which results in inhibition of mTOR signaling 
and Ras activity (Nair, et al., 2014). Curcumin inhibits the growth of Panc28 and L3.6pL pancreatic cancer cells, and tumor growth in nude mice bearing L3.6pL cells as xenografts (Jutooru, et al., 2010b). It reduces NFkB-dependent trans-activation, as well as the levels of Sp1, Sp3, and Sp4, which are over-expressed in those pancreatic cancer cells (Jutooru, et al., 2010b).

\subsection{Sp transcription factors in colorectal cancer}

Colorectal cancer is the second most common cause of cancer-related death in Western Europe (Torre, et al., 2015) and in the United States (Siegel, et al., 2015). Arsenic trioxide decreases the expression of Sp1, Sp3 and Sp4 proteins and Sp-dependent genes in colon cancer cell lines by decreasing mitochondrial membrane potential, and the induction of reactive oxygen species (Jutooru, et al., 2010c). It has been suggested that co-treatment of colon cancer with curcumin plus conventional chemotherapeutic agents like 5-fluorouracil could enhance the therapeutic effects in patients who have developed drug resistance (Noratto, et al., 2013).

Cyclooxygenase 2 (COX-2) inhibitors are non-steroidal anti-inflammatory drugs that can inhibit colon cancer growth and angiogenesis. Aspirin and other nonsteroidal anti-inflammatory drugs, including COX-2 inhibitors, have been identified as potential chemotherapeutic drugs that may favorably affect the inflammatory response in colorectal cancer (Park, et al., 2014).

Moreover, the antiangiogenic activity of aspirin and COX-2 inhibitors in colon cancer cells has been linked to activation of proteasome-dependent degradation of Sp protein factors (Abdelrahim \& Safe, 2005; Pathi, et al., 2012). In any case, additional studies are required to identify fully the role of anti-inflammatory agents in the management of patients with colorectal cancer (Park, et al., 2014). Inhibition of Sp1 transcription factor by siRNA or mithramycin A can suppress the growth of colon cancer stem cells, and this induces apoptosis in cells in culture and in xenografts (Zhao, et al., 2013).

In HCT116 human colon carcinoma cells, the mithramycin analogs MSK and DIG-MSK produce strong changes in gene expression (Bataller, et al., 2008; Vizcaíno, et al., 2012). Each analog down-regulates a different set of genes, although five genes are coincidentally down- 
regulated by both compounds (Vizcaíno, et al., 2012). All these genes can be potential therapeutic targets. MSK or DIG-MSK compete with Sp1 for binding to their putative binding sites (Vizcaíno, et al., 2012). Moreover, other genes are significantly up-regulated upon treatments, among them $p 21^{W A F 1}$ is involved in halting cells at the $\mathrm{G} 1$ and $\mathrm{G} 2 / \mathrm{M}$ checkpoints.

\subsection{Sp transcription factors in bladder cancer}

Bladder cancer is a common malignancy that causes hundreds of thousands of deaths worldwide each year (Siegel, et al., 2015; Torre, et al., 2015). Two human bladder cancer cell lines (KU7 and 253JB-V) have been used as models for investigating the molecular mechanisms associated with the anticancer activity of arsenic trioxide (Jutooru, et al., 2010c). This molecule reduces the expression of $\mathrm{Sp} 1, \mathrm{Sp} 3$ and $\mathrm{Sp} 4$ proteins in bladder cancer cells, yet growth inhibition could also be Sp-independent. Arsenic trioxide inhibits tumor growth in athymic mice bearing KU7 cells as xenografts. Such down-regulation of Sp, as well as of Sp-dependent genes, is a consequence of a decrease in the mitochondrial membrane potential and induction of ROS (Jutooru, et al., 2010c). Treatment of cancer cells derived from urologic (bladder and prostate) tumors with arsenic trioxide shows differential responsiveness to the antiproliferative effects of this molecule, which occurs in parallel with the differential repression of Sp1, Sp3 and Sp4 proteins in the same cell lines (Jutooru, et al., 2010c). The relationship between ROS and downregulation of Sp proteins has been examined in KU7 bladder carcinoma cells treated with hydrogen peroxide. Like arsenic trioxide, hydrogen peroxide inhibits the growth of KU7 cells and decreases the expression of Sp1, Sp3 and Sp4 proteins, while these responses are blocked after co-treatment with an antioxidant agent (Jutooru, et al., 2010c).

As mentioned above, curcumin induces proteasome-dependent reduction of Sp1, Sp3, and Sp4 in human bladder cancer cells (Chadalapaka, et al., 2008). Moreover, RNA interference, by using small inhibitory RNAs for Sp1, Sp3, and Sp4, has shown that the curcumin-dependent inhibition of NFkB-dependent genes, such as bcl-2, survivin, and cyclin D1, is also related to loss of Sp proteins (Jutooru, et al., 2010b). Overall, these results substantiate that the 
chemotherapeutic action of curcumin in bladder cancer cells can be ascribed to decreasing the expression of the Sp-family of transcription factors (Chadalapaka, et al., 2008; Jutooru, et al., 2010b).

\subsection{Sp transcription factors in prostate cancer}

In prostate cancer, which is among the more common epithelial cancers in men (Siegel, et al., 2015; Torre, et al., 2015), the prostate-specific antigen (PSA) is widely used as a serum marker for diagnosis, but it often leads to false positive results (Manne, et al., 2005), which makes necessary to identify new molecular biomarkers. Among them the Sp-factors are potential candidates.

Increased levels of Sp1/Sp3/FLIP seem to be related to resistance to apoptosis and progression to biochemical recurrence or to progression from low- to high-risk prostate cancer (Bedolla, et al., 2012). Sp1 and Sp3 participate in the transcriptional regulation of the antiapoptotic protein FLIP. The analysis of prostate tissues from patients with recurrent and nonrecurrent prostate cancer indicates that FLIP expression is positively regulated by Sp1 and that targeting Sp1/Sp3/FLIP could be used for the clinical management of prostate cancer (Bedolla, et al., 2012). Sp1 regulates crucial genes such as the androgen receptor, TGF- $\beta$ or c-Met, which highlights the importance of Sp1 in prostate cancer and the potential therapeutic value of targeting it (Sankpal, et al., 2011). Several strategies, including the use of natural and synthetic compounds, have been contemplated to inhibit Sp1 in prostate cancer (Sankpal, et al., 2011). Betulinic acid decreases the expression of VEGF and survivin in some prostate cells (Chintharlapalli, et al., 2007). So far, the antiangiogenic and pro-apoptotic responses induced by betulinic acid in human prostate cancer cells and in tumors derived from tissues is due to activation of selective proteasome-dependent degradation of Sp1, Sp3, and Sp4 transcription factors, which regulate VEGF and survivin expression (Chintharlapalli, et al., 2007). Arsenic trioxide inhibits the growth of prostate cancer cells through down-regulation of Sp and Spdependent genes, which is related to decreased mitochondrial membrane potential and the 
induction of ROS, as it does in bladder cancer (Jutooru, et al., 2010c). Besides, the modulation of Sp activity by some new mithramycin analogs might be important for the treatment of metastatic prostate cancer (Malek, et al., 2012). Moreover, in prostate cancer, there are grounds for considering future RNA interference therapy by identifying therapeutically viable transcription factor targets, such as Sp proteins (Fitzgerald, et al., 2014).

\subsection{Sp transcription factors in lung cancer}

Lung cancer is one of the most common cancers in the world and a leading cause of cancer death in men and women (Torre, et al., 2015). Enhanced Sp1 transcription drives basal and hypoxia-induced VEGF expression in non-small cell lung cancer (Colon, et al., 2011; Deacon, et al., 2012), while highly increased Sp1 levels are required for lung tumor growth in transgenic mice bearing Kras-induced lung tumors (Hsu, et al., 2012). Sp1 up-regulates the expression of CD147, a negative prognostic factor that plays an important role in the invasion and metastasis of human lung cancer. CD147 expression can be impaired by mithramycin A (Kong, et al., 2010). On the other hand, Sp1, which is required for lung tumor growth, might, however, display a tumor-suppressor-like activity in late stage lung tumors (Hsu, et al., 2012).

Tolfenamic acid decreases the expression of $c$-Met — aberrantly active Met can trigger tumor growth and angiogenesis - promoting the degradation of Sp proteins, and it inhibits lung cancer cells growth as well as tumorigenesis in orthotopic mice (Colon, et al., 2011). Indeed, immunohistochemical staining of pathological lung tissue in orthotopic mice reveals high expression of Sp1, Sp3, Sp4 and c-Met in the control, untreated, group, and a dose-dependent decrease in the group treated with tolfenamic acid (Colon, et al., 2011). These observations suggest that targeting $c$-Met by an inhibitor of Sp proteins may become a strategy for the treatment of lung cancer. Hence, tolfenamic acid could be used as a therapeutic agent for lung cancer. Of interest, the treatment with mithramycin A under conditions that could be achieved in clinical settings diminishes basal and cigarette smoke condensate-mediated increases in Sp1 levels within the promoter of the gene encoding for the ABCG2 (ATP-binding cassette, sub- 
family G2) transporter, down-regulating it while inhibiting proliferation and tumorigenicity of lung and esophageal cancer cells (Zhang, et al., 2012).

$\beta$-elemene, a natural molecule isolated from Rhizoma zedoariae, inhibits the growth of human lung cancer cells via ERK1/2- and AMPK $\alpha$-mediated inhibition of Sp1, followed by reduction in the DNA methyltransferase 1 protein levels (Zhao, et al., 2015).

\subsection{Sp transcription factors in breast cancer}

The Sp-family of transcription factors is considered a prognostic tool in breast cancer (Wright, et al., 1987). Nevertheless, the role of Sp1 in breast cancer is still a controversial issue because $\mathrm{Sp} 1$ is over-expressed in some patients as a negative prognostic factor (Wang, et al., 2007), while silencing of Sp1 is observed in advanced breast cancer (Li, et al., 2014b). It has been suggested that targeted therapy against Sp1 might be useful in the early stage breast cancer, while the development of Sp1 activators may be more useful for treating the late stages of breast cancer (Li, et al., 2014b). High expression of the transcription repressor ZBTB4 is contemplated as a favorable prognostic factor for relapse free survival of breast cancer patients (Kim, et al., 2012; Yang, et al., 2014b). It has been established that variations in the Sp1-binding sites in the survivin promoter are after the over-expression of this gene that is observed in many human breast cancer tissues $(\mathrm{Xu}$, et al., 2014).

DIM (3,3'-Diindolylmethane) is a potential cancer chemopreventive compound that shows direct growth inhibitory effect on human estrogen-dependent (MCF-7) and estrogen-independent (MDA-MB231) breast cancer cell lines (Hong, et al., 2002), increasing the proportion of cells in the G1 phase of the cell cycle, regardless of the estrogen-receptor status. Concurrent with the DIM-induced cell cycle arrest, DIM stimulated a rapid and pronounced increase in levels of the CDK inhibitor $\mathrm{p} 21^{\mathrm{WAF} 1}$, and this induction of $\mathrm{p} 21^{\mathrm{WAF} 1}$ expression appears to be independent of estrogen-receptor signaling and of p53 (Hong, et al., 2002). In MDA-MB-231 human breast carcinoma cells, the effects of bisanthracycline WP631 on Sp1-activated transcription includes changes in the expression of $c-m y c$ and $p 21^{W A F 1}$, and in the levels of their encoded proteins, which 
are consistent with that cell cycle progression through G2 commits cells to dying through mitotic catastrophe (Mansilla, et al., 2006a). A quantitative RT-PCR study of around one hundred genes, most of them involved in the control of cell cycle progression, indicates that human MDAMB231 cells treated with bisanthracycline WP631 present a profile of gene down-regulation that differs from that caused by Sp1 knockdown obtained using a specific shRNA (Mansilla, et al., 2011). Genes down-regulated upon treatment with WP631 or doxorubicin, or after Sp1 knockdown, have been mapped to their molecular and biological functions, which documents the down-regulation of genes involved in mRNA transcription regulation (Mansilla, et al., 2011). The changes in gene expression caused by the ability of doxorubicin or WP631 to compete with Sp1 for binding to DNA differ from those produced by Sp1 knockdown. WP631 produces a profile of gene down-regulation markedly different. These observations have been rationalized by considering a near-specific effect of WP631 on the Sp1 interaction with several gene promoters, which could represent potential therapeutic targets for WP631, in contrast to a less specific genome-wide effect of reducing the availability of Sp1 molecules through RNA interference (Mansilla, et al., 2011).

The rise of tumors resistant to conventional chemotherapy is a major concern in the fight against breast cancer. Mithramycin A could sensitize breast cancer stem cells against the anthracycline doxorubicin, which is widely used in combined treatments against breast carcinomas (Saha, et al., 2015). Moreover, mithramycin A can produce the transcriptional inhibition of cancer stem cells by inhibiting Sp1 recruitment to gene promoters (Saha, et al., 2015). In the presence of mithramycin A, doxorubicin would induce apoptosis in breast cancer stem cells through the generation of ROS-mediated DNA damage. Mithramycin A might be considered, therefore, as a promising drug in combinatorial therapy with other existing chemotherapeutic agents that fail to eliminate cancer stem cells (Saha, et al., 2015).

Bisanthracycline WP631 circumvents the multidrug-resistance MRP-1 protein in MCF-7/VP cells, thus avoiding the efflux pump (Mansilla, et al., 2007). This specific cytotoxicity is 
enhanced by the direct effect of WP631 on gene transcription (Mansilla, et al., 2007). MRP-1 is encoded by the mrp-1 gene that is regulated by Sp1, and Sp1-binding to DNA is strongly inhibited by WP631 (Mansilla, et al., 2007). WP631 might, therefore, be a drug with potential clinical interest in the treatment of breast malignancies that display certain multidrug-resistance phenotypes.

\subsection{Sp transcription factors in ovarian cancer}

Advanced ovarian cancer has a poor prognosis and late diagnosis for most patients (Hennessy, et al., 2009; Siegel, et al., 2015). In ovarian cancer cells, key roles of Sp1 have been described, for example, in the regulation of the heparin-binding epidermal growth factor-like growth factor (HB-EGF), a promising target for ovarian cancer therapy (Miyata, et al., 2014), and of the promoter of CLDN4 (claudin-4), a gene over-expressed in ovarian cancer (Honda, et al., 2006). The CLDN4 promoter is further controlled by epigenetic modifications of the Sp1containing critical promoter region (Honda, et al., 2006).

Tolfenamic acid inhibits ovarian cancer cell growth (Basha, et al., 2011), as in other tumor cell types (Colon, et al., 2011) this molecule targets c-Met through the degradation of Sp proteins.

In ovarian cancer, both toxicity and antitumor activity of several mithramycin analogs have been investigated in nude mice bearing human ovarian tumors (Núñez, et al., 2012; Previdi, et al., 2010), as well as in human cell lines (Albertini, et al., 2006; Fernández-Guizán, et al., 2014; Vizcaíno, et al., 2014). The novel mithramycin analog MSK (Fig. 3) represses transcription of a host of genes involved in key aspects of cancer development, including the control of cell cycle, angiogenesis and apoptosis (Albertini, et al., 2006). In A2780 human ovarian cancer cells, nanomolar concentrations of the novel analog DIG-MSK (Fig. 3) abrogate the expression of genes involved in several cellular processes including transcription regulation and tumor development, activating cell death pathways (Vizcaíno, et al., 2014). Sp1 transcription factor regulates most of the genes grouped in the gene ontology $(\mathrm{GO})$ categories compiled in Fig. 4, which are down-regulated by the drug (Vizcaíno, et al., 2014). Many of the down-regulated genes 
are involved in cell proliferation and poor prognosis in ovarian cancer. Moreover, Sp1 could also participate in the up-regulation of other genes mainly involved in response to cell stress (Vizcaíno, et al., 2014). MSK and MSDK (Fig. 3) are potent inhibitors of Sp1-dependent transcription both in vitro and in tumor xenografts (Fernández-Guizán, et al., 2014; Previdi, et al., 2010). In mice, MSK and MSDK delay growth of ovarian tumor xenografts and they are well tolerated, even after prolonged administration (Previdi, et al., 2010). Expression of Sp1 and target proteins in ovarian cancer specimens and tumor xenografts has been examined by immunohistochemistry after treatment with those compounds (Previdi, et al., 2010). MSDK seems to be particularly effective against orthotopic tumors, leading to a significant increase of survival and delay of tumor progression (Previdi, et al., 2010), which is consistent with the downregulation of genes that are trans-activated by Sp1. On the whole, the new mithramycin analogs, MSK, MSDK and DIG-MSK, may become stunning candidates for treatment of ovarian cancer (Previdi, et al., 2010; Vizcaíno, et al., 2014). Besides, WP631, which, as mentioned above, is a strong inhibitor of Sp1-transactivated transcription (Portugal, et al., 2001), induces caspasedependent apoptosis in human ovarian cancer cells (Gajek, et al., 2014).

\subsection{Sp transcription factors in other cancers}

Significant biological roles of $\mathrm{Sp} 1$ trans-activation, and of the different members of the Spfamily of transcription factors, have also been revealed for tumors and tumor cell lines other than those described in the previous paragraphs. For the sake of example, we will mention this is the case of multiple myeloma (Fulciniti, et al., 2011) and esophageal cancer (O'Sullivan-Coyne, et al., 2009; Papineni, et al., 2009; Zhang, et al., 2012). Interestingly, the down-regulation of Sp1 suppresses cell proliferation, clonogenicity and the expression of stem cell markers in nasopharyngeal carcinoma (Zhang, et al., 2014).

$\mathrm{Sp} 1, \mathrm{Sp} 3, \mathrm{Sp} 4$ and several pro-oncogenic Sp-regulated genes are over-expressed in rhabdomyosarcoma, a common soft-tissue cancer that is primarily observed in young people (Chadalapaka, et al., 2013). Tolfenamic acid inhibits the growth of rhabdomyosarcoma cells and 
tumor xenografts, which is accompanied by Sp protein down-regulation (Chadalapaka, et al., 2013). This molecule also possesses anti-leukemic activity (Sutphin, et al., 2014). Furthermore, $\mathrm{Sp} 1$ activation has been proposed as a putative marker for aggressiveness of glioblastoma (Lee, et al., 2014). Sp1 participates in the in vivo transcription factor recruitment during thyroid hormone receptor-mediated activation (Kim, et al., 1999). Some drugs that decrease Sp protein expression down-regulate the pro-oncogenic PTTG-1 factor in thyroid cancer cells and, thus, they are of potential interest for the clinical treatment of thyroid cancer (Chintharlapalli, et al., 2011a; Kim, et al., 1999).

\section{Conclusions and perspectives}

Sp1 and its family of related protein factors are implicated in a variety of essential biological processes, such as cell growth, differentiation, carcinogenesis and apoptosis. Sp1 and Sp3 interact with GC-boxes (consensus sequence: 5'-(G/T)GGGCGG(G/A)(G/A)(C/T)-3') found in gene promoters. In human cells, Sp1 acts as gene activator, while $\mathrm{Sp} 3$ can be either be a repressor or activator (Li, et al., 2004). The transcriptional activity of Sp1 is regulated by several posttranscriptional modifications and by its interaction with other proteins, including transcription factors, oncogenes, and tumor suppressors (Li \& Davie, 2010; Wierstra, 2008). Sp1 target genes belong to the hallmarks of cancer (Beishline \& Azizkhan-Clifford, 2015; Hanahan \& Weinberg, 2011). Here, we have reviewed how several experimentally and clinically used compounds downregulate $\mathrm{Sp} 1, \mathrm{Sp} 3$ and $\mathrm{Sp} 4$ as well as Sp-regulated genes in cancer cells in culture and xenografts of human tumors in mice. Also, we have summarized several examples of the prognostic significance of the Sp-family of transcription factors in patients with diverse types of cancers. In general, $\mathrm{Sp} 1$ over-expression is considered a negative prognostic factor in cancer as it can enhance both the proliferative and metastatic phenotypes (Guan, et al., 2012; Safe \& Abdelrahim, 2005; Sankpal, et al., 2012; Wang, et al., 2003; Wierstra, 2008).

Increasing evidence suggests that transcription factors are vulnerable elements in almost all types of cancer (Frank, 2009), while reducing expression of the Sp-family of proteins attenuates 
the expression of genes involved in driving the cancer process (Safe, et al., 2014). Several anticancer agents in clinical use, such as some anthracyclines or mithramycin A, and a variety of experimental drugs — which includes novel mithramycin analogs obtained by recombinant biosynthesis — alter the binding of Sp1/Sp3 to DNA (Chiang, et al., 1998; Fernández-Guizán, et al., 2014; Mansilla \& Portugal, 2008; Portugal, et al., 2011). Moreover, they are active on several pro-oncogenic and angiogenic Sp-regulated genes in cancer cell lines and in human tumor xenografts in nude mice (Malek, et al., 2012; Portugal, et al., 2001; Safe, et al., 2014; Wang, et al., 2008a). Among the genes identified to be down-regulated by DNA-binding drugs, VEGF, XIAP, survivin, or c-myc illustrate direct drug effects on key genes in cancer development, which can occur via interference with Sp transcription factors (Albertini, et al., 2006; Previdi, et al., 2010; Vizcaíno, et al., 2014; Xu, et al., 2007).

Furthermore, numerous compounds have been reported to affect the intervention of $\mathrm{Sp}$ transcription factors in cancer cell growth without a direct effect on DNA-protein interaction, which can occur through different pathways that depend on the target cancer cell. So far, induction of ROS by several anticancer drugs can decrease the expression of Sp transcription factors through down-regulation of microRNA 27a (miR-27a)/miR-20a:miR-17-5p and induction of the miR-regulated Sp repressors ZBTB10, ZBTB4 and ZBTB34. These repressors would compete with Sp transcription factors for their putative CG-rich binding sites to abrogate gene trans-activation (Chintharlapalli, et al., 2011b; Jutooru, et al., 2010c; Jutooru, et al., 2014; Noratto, et al., 2013). Moreover, down-regulation of Sp proteins by caspase cleavage or by the activation of the proteasome has been reported (Abdelrahim \& Safe, 2005; Chadalapaka, et al., 2008; Chintharlapalli, et al., 2011b; Pathi, et al., 2012; Piedrafita \& Pfahl, 1997). Curcumin, which induces proteasome-dependent down-regulation of Sp proteins in bladder cancer cells (Chadalapaka, et al., 2008), decreases the expression of Sp1, Sp3, and Sp4 in pancreatic cancer through a ROS-dependent pathway (Jutooru, et al., 2010b). Tolfenamic acid and related nonsteroidal anti-inflammatory drugs, induce proteasome-dependent degradation of Sp1, Sp3 and 
$\mathrm{Sp} 4$, while the combined treatment of pancreatic tumor xenografts with mithramycin A and tolfenamic acid promotes Sp1 degradation and synergistic antitumor activity (Jia, et al., 2010). There are evidences of other pathways participating in Sp1 down-regulation, which are under investigation (Safe, et al., 2014). Following the finding that mithramycin A not only binds to DNA, but it could also decrease Sp1 protein levels by inducing proteasome-dependent degradation through a DR5/caspase-8/Bid signalling pathway (Choi, et al., 2014), it should be considered that a close relationship and crosstalk might exist among the different mechanisms of action of small molecules acting on the Sp-family of transcription factors.

Many of the drugs and natural molecules reviewed here can be considered safe enough (D'Incalci, et al., 2007; Minotti, et al., 2004; Núñez, et al., 2012; Sankpal, et al., 2013), which would support or accelerate their clinical usage. However, experimental data should be handled with care in translational medicine based on inhibiting Sp transcription factors, given that Sp1 and/or Sp3 can cooperatively activate several genes through the interaction with other transcription factors or their DNA-binding sites (Safe \& Abdelrahim, 2005; Vizcaíno, et al., 2012; Wierstra, 2008). Compounds that challenge Sp-binding to DNA may also target the binding of other transcription factors, thus producing potentially undesirable out-of-target effects (Chiang, et al., 1998; Safe \& Abdelrahim, 2005; Vizcaíno, et al., 2012). Whatever the case, although we know very little about how cells may response to acute inhibition of transcription, it is conceivable that normal cells could be more tolerant to transient inhibition of transcription, whereas tumor cells are highly vulnerable (Bywater, et al., 2013). In this context, it is not surprising that many drugs that have been in clinical use since long time ago, such the anthracyclines or some alkylating agents, are compounds that somehow target transcription, including Sp-transactivated transcription, among other cellular events (Gniazdowski, et al., 2005; Hurley, 2002; Mansilla \& Portugal, 2008).

Future developments of therapies based on down-regulating the function of $\mathrm{Sp}$ transcription factors will first require an increased understanding of the role and significance of drug-induced 
Sp down-regulation and the design of more effective drugs. Clinical studies are required to ascertain the effect of cancer therapy regimens on Sp1 signaling in tumors, and the ability of Sp1targeting strategies to modify cancer responses. It is also needed to identify patients that could benefit from treatment with drugs targeting the down-regulation of Sp1. It is likely that only patients with tumors that over-express $\mathrm{Sp} 1$ would benefit from treatment with antineoplastic agents that down-regulate this protein and/or its effects on gene expression (Safe, et al., 2014). A large-scale characterization of natural products, including 'nutraceuticals', which could act as modulators of gene transcription by altering the activity of the Sp-family of transcription factors seems a realistic and attractive approach to discover compounds therapeutically effective against various types of cancer that show specific aberrations in the regulation of gene expression.

\section{Conflict of interest statement}

The authors declare that there are no conflicts of interest.

\section{Acknowledgements}

We apologize to the authors whose original publications have not been cited due to scope and space limitations. Carolina Vizcaíno was recipient of a JAE-Predoc2010 fellowship (CSIC), cofinanced by the European Social Fund.

\section{References}

Abdelrahim, M., Baker, C. H., Abbruzzese, J. L., \& Safe, S. (2006). Tolfenamic acid and pancreatic cancer growth, angiogenesis, and Sp protein degradation. J Natl Cancer Inst, $98,855-868$

Abdelrahim, M., \& Safe, S. (2005). Cyclooxygenase-2 inhibitors decrease vascular endothelial growth factor expression in colon cancer cells by enhanced degradation of Sp1 and Sp4 proteins. Mol Pharmacol, 68, 317-329. 
Abdelrahim, M., Smith, R., 3rd, Burghardt, R., \& Safe, S. (2004). Role of Sp proteins in regulation of vascular endothelial growth factor expression and proliferation of pancreatic cancer cells. Cancer Res, 64, 6740-6749.

Albertini, V., Jain, A., Vignati, S., Napoli, S., Rinaldi, A., Kwee, I., et al. (2006). Novel GC-rich DNA-binding compound produced by a genetically engineered mutant of the mithramycin producer Streptomyces argillaceus exhibits improved transcriptional repressor activity: implications for cancer therapy. Nucleic Acids Res, 34, 1721-1734.

Ammanamanchi, S., Freeman, J. W., \& Brattain, M. G. (2003). Acetylated Sp3 is a transcriptional activator. J Biol Chem, 278, 35775-35780.

Azizkhan, J. C., Jensen, D. E., Pierce, A. J., \& Wade, M. (1993). Transcription from TATA-less promoters: dihydrofolate reductase as a model. Crit Rev Eukaryot Gene Expr, 3, 229-254.

Barceló, F., Ortiz-Lombardía, M., Martorell, M., Oliver, M., Méndez, C., Salas, J. A., et al. (2010). DNA binding characteristics of mithramycin and chromomycin analogues obtained by combinatorial biosynthesis. Biochemistry, 49, 10543-10552.

Barceló, F., Scotta, C., Ortiz-Lombardía, M., Méndez, C., Salas, J. A., \& Portugal, J. (2007). Entropically-driven binding of mithramycin in the minor groove of C/G-rich DNA sequences. Nucleic Acids Res, 35, 2215-2226.

Basha, R., Ingersoll, S. B., Sankpal, U. T., Ahmad, S., Baker, C. H., Edwards, J. R., et al. (2011). Tolfenamic acid inhibits ovarian cancer cell growth and decreases the expression of c-Met and survivin through suppressing specificity protein transcription factors. Gynecol Oncol, $122,163-170$.

Bataller, M., Méndez, C., Salas, J. A., \& Portugal, J. (2008). Mithramycin SK modulates polyploidy and cell death in colon carcinoma cells. Mol Cancer Ther, 7, 2988-2997.

Bedolla, R. G., Gong, J., Prihoda, T. J., Yeh, I. T., Thompson, I. M., Ghosh, R., et al. (2012). Predictive value of Sp1/Sp3/FLIP signature for prostate cancer recurrence. PLoS ONE, 7, e44917. 
Beishline, K., \& Azizkhan-Clifford, J. (2015). Sp1 and the 'hallmarks of cancer'. FEBS J, 282, 224-258.

Black, A. R., Jensen, D., Lin, S. Y., \& Azizkhan, J. C. (1999). Growth/Cell cycle regulation of Sp1 phosphorylation. J Biol Chem, 274, 1207-1215.

Botella, L. M., Sánchez-Elsner, T., Rius, C., Corbi, A., \& Bernabéu, C. (2001). Identification of a critical Sp1 site within the endoglin promoter and its involvement in the transforming growth factor- $\beta$ stimulation. J Biol Chem, 276, 34486-34494.

Bretones, G., Delgado, M. D., \& León, J. (2015). Myc and cell cycle control. Biochim Biophys Acta, 1849, 506-516.

Bywater, M. J., Pearson, R. B., McArthur, G. A., \& Hannan, R. D. (2013). Dysregulation of the basal RNA polymerase transcription apparatus in cancer. Nat Rev Cancer, 13, 299-314.

Chadalapaka, G., Jutooru, I., Chintharlapalli, S., Papineni, S., Smith, R., 3rd, Li, X., et al. (2008). Curcumin decreases specificity protein expression in bladder cancer cells. Cancer Res, 68, $5345-5354$.

Chadalapaka, G., Jutooru, I., Sreevalsan, S., Pathi, S., Kim, K., Chen, C., et al. (2013). Inhibition of rhabdomyosarcoma cell and tumor growth by targeting specificity protein ( $\mathrm{Sp}$ ) transcription factors. Int J Cancer, 132, 795-806.

Chaires, J. B., Herrera, J. E., \& Waring, M. J. (1990). Preferential binding of daunomycin to 5'ATCG and 5'ATGC sequences revealed by footprinting titration experiments. Biochemistry, 29, 6145-6153.

Chaires, J. B., Leng, F. F., Przewloka, T., Fokt, I., Ling, Y. H., Perez-Soler, R., et al. (1997). Structure-based design of a new bisintercalating anthracycline antibiotic. $J$ Med Chem, 40, 261-266.

Chiang, S. Y., Azizkhan, J. C., \& Beerman, T. A. (1998). A comparison of DNA-binding drugs as inhibitors of E2F1- and Sp1-DNA complexes and associated gene expression.

Biochemistry, 37, 3109-3115. 
Chintharlapalli, S., Papineni, S., Lee, S. O., Lei, P., Jin, U. H., Sherman, S. I., et al. (2011a). Inhibition of pituitary tumor-transforming gene-1 in thyroid cancer cells by drugs that decrease specificity proteins. Mol Carcinog, 50, 655-667.

Chintharlapalli, S., Papineni, S., Lei, P., Pathi, S., \& Safe, S. (2011b). Betulinic acid inhibits colon cancer cell and tumor growth and induces proteasome-dependent and -independent downregulation of specificity proteins (Sp) transcription factors. BMC Cancer, 11, 371 .

Chintharlapalli, S., Papineni, S., Ramaiah, S. K., \& Safe, S. (2007). Betulinic acid inhibits prostate cancer growth through inhibition of specificity protein transcription factors. Cancer Res, 67, 2816-2823.

Choi, E. S., Nam, J. S., Jung, J. Y., Cho, N. P., \& Cho, S. D. (2014). Modulation of specificity protein 1 by mithramycin A as a novel therapeutic strategy for cervical cancer. Sci Rep, 4, 7162.

Chu, S. (2012). Transcriptional regulation by post-transcriptional modification--role of phosphorylation in Sp1 transcriptional activity. Gene, 508, 1-8.

Colon, J., Basha, M. R., Madero-Visbal, R., Konduri, S., Baker, C. H., Herrera, L. J., et al. (2011). Tolfenamic acid decreases c-Met expression through Sp proteins degradation and inhibits lung cancer cells growth and tumor formation in orthotopic mice. Invest New Drugs, 29, 41-51.

Courey, A. J., Holtzman, D. A., Jackson, S. P., \& Tjian, R. (1989). Synergistic activation by the glutamine-rich domains of human transcription factor Sp1. Cell, 59, 827-836.

Crijns, A. P., Fehrmann, R. S., de Jong, S., Gerbens, F., Meersma, G. J., Klip, H. G., et al. (2009). Survival-related profile, pathways, and transcription factors in ovarian cancer. PLoS Med, 6, e1000024.

D'Incalci, M., Brunelli, D., Marangon, E., Simone, M., Tavecchio, M., Gescher, A., et al. (2007). Modulation of gene transcription by natural products - a viable anticancer strategy. Curr Pharm Des, 13, 2744-2750. 
Dalvai, M., Mondesert, O., Bugler, B., Manenti, S., Ducommun, B., \& Dozier, C. (2013). Doxorubicin promotes transcriptional upregulation of Cdc25B in cancer cells by releasing Sp1 from the promoter. Oncogene, 32, 5123-5128.

Deacon, K., Onion, D., Kumari, R., Watson, S. A., \& Knox, A. J. (2012). Elevated Sp-1 transcription factor expression and activity drives basal and hypoxia-induced vascular endothelial growth factor (VEGF) expression in non-small cell lung cancer. J Biol Chem, 287, 39967-39981.

Deniaud, E., Baguet, J., Chalard, R., Blanquier, B., Brinza, L., Meunier, J., et al. (2009).

Overexpression of transcription factor $\mathrm{Sp} 1$ leads to gene expression perturbations and cell cycle inhibition. PLoS ONE, 4, e7035.

Deniaud, E., Baguet, J., Mathieu, A. L., Pages, G., Marvel, J., \& Leverrier, Y. (2006).

Overexpression of Sp1 transcription factor induces apoptosis. Oncogene, 25, 7096-7105.

Doetzlhofer, A., Rotheneder, H., Lagger, G., Koranda, M., Kurtev, V., Brosch, G., et al. (1999). Histone deacetylase 1 can repress transcription by binding to Sp1. Mol Cell Biol, 19, $5504-5511$.

Essafi-Benkhadir, K., Grosso, S., Puissant, A., Robert, G., Essafi, M., Deckert, M., et al. (2009). Dual role of Sp3 transcription factor as an inducer of apoptosis and a marker of tumour aggressiveness. PLoS ONE, 4, e4478.

Estève, P. O., Chin, H. G., \& Pradhan, S. (2007). Molecular mechanisms of transactivation and doxorubicin-mediated repression of survivin gene in cancer cells. J Biol Chem, 282, 26152625 .

Fandos, C., Sánchez-Feutrie, M., Santalucía, T., Viñals, F., Cadefau, J., Gumà, A., et al. (1999). GLUT1 glucose transporter gene transcription is repressed by Sp3. Evidence for a regulatory role of Sp3 during myogenesis. J Mol Biol, 294, 103-119.

Feng, X. H., Lin, X., \& Derynck, R. (2000). Smad2, Smad3 and Smad4 cooperate with Sp1 to induce p15(Ink4B) transcription in response to TGF- $\beta . E M B O J, 19,5178-5193$. 
Fernández-Guizán, A., Mansilla, S., Barceló, F., Vizcaíno, C., Núñez, L. E., Morís, F., et al. (2014). The activity of a novel mithramycin analog is related to its binding to DNA, cellular accumulation, and inhibition of Sp1-driven gene transcription. Chem Biol Interact, 219, 123-132.

Fitzgerald, K. A., Evans, J. C., McCarthy, J., Guo, J., Prencipe, M., Kearney, M., et al. (2014). The role of transcription factors in prostate cancer and potential for future RNA interference therapy. Expert Opin Ther Targets, 18, 633-649.

Fojas-de-Borja, P., Collins, N. K., Du, P., Azizkhan-Clifford, J., \& Mudryj, M. (2001). Cyclin ACDK phosphorylates Sp1 and enhances Sp1-mediated transcription. EMBO J, 20, 57375747.

Frank, D. A. (2009). Targeting transcription factors for cancer therapy. IDrugs, 12, 29-33.

Frederick, C. A., Williams, L. D., Ughetto, G., van der Marel, G. A., van Boom, J. H., Rich, A., et al. (1990). Structural comparison of anticancer drug-DNA complexes: adriamycin and daunomycin. Biochemistry, 29, 2538-2549.

Fulciniti, M., Amin, S., Nanjappa, P., Rodig, S., Prabhala, R., Li, C., et al. (2011). Significant biological role of Sp1 transactivation in multiple myeloma. Clin Cancer Res, 17, 65006509.

Gajek, A., Denel, M., Bukowska, B., Rogalska, A., \& Marczak, A. (2014). Pro-apoptotic activity of new analog of anthracyclines--WP631 in advanced ovarian cancer cell line. Toxicol In Vitro, 28, 273-281

Gao, Y., Jia, Z., Kong, X., Li, Q., Chang, D. Z., Wei, D., et al. (2011). Combining betulinic acid and mithramycin a effectively suppresses pancreatic cancer by inhibiting proliferation, invasion, and angiogenesis. Cancer Res, 71, 5182-5193.

Gilmour, J., Assi, S. A., Jaegle, U., Kulu, D., van de Werken, H., Clarke, D., et al. (2014). A crucial role for the ubiquitously expressed transcription factor $\mathrm{Sp} 1$ at early stages of hematopoietic specification. Development, 141, 2391-2401. 
Gniazdowski, M., Denny, W. A., Nelson, S. M., \& Czyz, M. (2005). Effects of anticancer drugs on transcription factor-DNA interactions. Expert Opin Ther Targets, 9, 471-489.

Göllner, H., Dani, C., Phillips, B., Philipsen, S., \& Suske, G. (2001). Impaired ossification in mice lacking the transcription factor Sp3. Mech Dev, 106, 77-83.

Grohar, P. J., \& Helman, L. J. (2013). Prospects and challenges for the development of new therapies for Ewing sarcoma. Pharmacol Ther, 137, 216-224.

Guan, H., Cai, J., Zhang, N., Wu, J., Yuan, J., Li, J., et al. (2012). Sp1 is upregulated in human glioma, promotes MMP-2-mediated cell invasion and predicts poor clinical outcome. Int $J$ Cancer, 130, 593-601.

Gullett, N. P., Ruhul Amin, A. R., Bayraktar, S., Pezzuto, J. M., Shin, D. M., Khuri, F. R., et al. (2010). Cancer prevention with natural compounds. Semin Oncol, 37, 258-281.

Hagen, G., Muller, S., Beato, M., \& Suske, G. (1992). Cloning by recognition site screening of two novel GT box binding proteins: a family of Sp1 related genes. Nucleic Acids Res, 20, $5519-5525$.

Hagiwara, H., Iyo, M., \& Hashimoto, K. (2009). Mithramycin protects against dopaminergic neurotoxicity in the mouse brain after administration of methamphetamine. Brain Res, 1301, 189-196.

Hanahan, D., \& Weinberg, R. A. (2011). Hallmarks of cancer: the next generation. Cell, 144, 646-674.

He, S., \& Davie, J. R. (2006). Sp1 and Sp3 foci distribution throughout mitosis. J Cell Sci, 119, 1063-1070.

Hennessy, B. T., Coleman, R. L., \& Markman, M. (2009). Ovarian cancer. Lancet, 374, 13711382.

Honda, H., Pazin, M. J., Ji, H., Wernyj, R. P., \& Morin, P. J. (2006). Crucial roles of Sp1 and epigenetic modifications in the regulation of the CLDN4 promoter in ovarian cancer cells. J Biol Chem, 281, 21433-21444. 
Hong, C., Kim, H. A., Firestone, G. L., \& Bjeldanes, L. F. (2002). 3,3'-Diindolylmethane (DIM) induces a $\mathrm{G}(1)$ cell cycle arrest in human breast cancer cells that is accompanied by Sp1mediated activation of p21(WAF1/CIP1) expression. Carcinogenesis, 23, 1297-1305.

Hsu, T. I., Wang, M. C., Chen, S. Y., Yeh, Y. M., Su, W. C., Chang, W. C., et al. (2012). Sp1 expression regulates lung tumor progression. Oncogene, 31, 3973-3988.

Hurley, L. H. (2002). DNA and its associated processes as targets for cancer therapy. Nat Rev Cancer, 2, 188-200.

Ishibashi, H., Nakagawa, K., Onimaru, M., Castellanous, E. J., Kaneda, Y., Nakashima, Y., et al. (2000). Sp1 decoy transfected to carcinoma cells suppresses the expression of vascular endothelial growth factor, transforming growth factor $\beta 1$, and tissue factor and also cell growth and invasion activities. Cancer Res, 60, 6531-6536.

Jia, Z., Gao, Y., Wang, L., Li, Q., Zhang, J., Le, X., et al. (2010). Combined treatment of pancreatic cancer with mithramycin A and tolfenamic acid promotes Sp1 degradation and synergistic antitumor activity. Cancer Res, 70, 1111-1119.

Jia, Z., Zhang, J., Wei, D., Wang, L., Yuan, P., Le, X., et al. (2007). Molecular basis of the synergistic antiangiogenic activity of bevacizumab and mithramycin A. Cancer Res, 67, $4878-4885$.

Jiang, N. Y., Woda, B. A., Banner, B. F., Whalen, G. F., Dresser, K. A., \& Lu, D. (2008). Sp1, a new biomarker that identifies a subset of aggressive pancreatic ductal adenocarcinoma. Cancer Epidemiol Biomarkers Prev, 17, 1648-1652.

Jiang, Y., Wang, L., Gong, W., Wei, D., Le, X., Yao, J., et al. (2004). A high expression level of insulin-like growth factor I receptor is associated with increased expression of transcription factor $\mathrm{Sp} 1$ and regional lymph node metastasis of human gastric cancer. Clin Exp Metastasis, 21, 755-764.

Jutooru, I., Chadalapaka, G., Abdelrahim, M., Basha, M. R., Samudio, I., Konopleva, M., et al. (2010a). Methyl 2-cyano-3,12-dioxooleana-1,9-dien-28-oate decreases specificity protein 
transcription factors and inhibits pancreatic tumor growth: role of microRNA-27a. Mol Pharmacol, 78, 226-236.

Jutooru, I., Chadalapaka, G., Lei, P., \& Safe, S. (2010b). Inhibition of NFאB and pancreatic cancer cell and tumor growth by curcumin is dependent on specificity protein downregulation. J Biol Chem, 285, 25332-25344.

Jutooru, I., Chadalapaka, G., Sreevalsan, S., Lei, P., Barhoumi, R., Burghardt, R., et al. (2010c). Arsenic trioxide downregulates specificity protein $(\mathrm{Sp})$ transcription factors and inhibits bladder cancer cell and tumor growth. Exp Cell Res, 316, 2174-2188.

Jutooru, I., Guthrie, A. S., Chadalapaka, G., Pathi, S., Kim, K., Burghardt, R., et al. (2014). Mechanism of action of phenethylisothiocyanate and other reactive oxygen speciesinducing anticancer agents. Mol Cell Biol, 34, 2382-2395.

Kadonaga, J. T., Jones, K. A., \& Tjian, R. (1986). Promoter-specific activation of RNA polymerase II transcription by Sp1. Trends Biochem Sci, 11, 20-23.

Kennett, S. B., Udvadia, A. J., \& Horowitz, J. M. (1997). Sp3 encodes multiple proteins that differ in their capacity to stimulate or repress transcription. Nucleic Acids Res, 25, 31103117.

Kim, K., Chadalapaka, G., Lee, S. O., Yamada, D., Sastre-Garau, X., Defossez, P. A., et al. (2012). Identification of oncogenic microRNA-17-92/ZBTB4/specificity protein axis in breast cancer. Oncogene, 31, 1034-1044.

Kim, M. K., Lee, J. S., \& Chung, J. H. (1999). In vivo transcription factor recruitment during thyroid hormone receptor-mediated activation. Proc Natl Acad Sci USA, 96, 10092-10097.

King, P. D., \& Perry, M. C. (2001). Hepatotoxicity of chemotherapy. Oncologist, 6, 162-176.

Kong, L. M., Liao, C. G., Fei, F., Guo, X., Xing, J. L., \& Chen, Z. N. (2010). Transcription factor Sp1 regulates expression of cancer-associated molecule CD147 in human lung cancer. Cancer Sci, 101, 1463-1470. 
Koutsodontis, G., \& Kardassis, D. (2004). Inhibition of p53-mediated transcriptional responses by mithramycin A. Oncogene, 23, 9190-9200.

Koutsodontis, G., Moustakas, A., \& Kardassis, D. (2002). The role of Sp1 family members, the proximal GC-rich motifs, and the upstream enhancer region in the regulation of the human cell cycle inhibitor p21WAF-1/Cip1 gene promoter. Biochemistry, 41, 12771-12784.

Krüger, I., Vollmer, M., Simmons, D. G., Elsasser, H. P., Philipsen, S., \& Suske, G. (2007). $\mathrm{Sp} 1 / \mathrm{Sp} 3$ compound heterozygous mice are not viable: impaired erythropoiesis and severe placental defects. Dev Dyn, 236, 2235-2244.

Lee, K., Qian, D. Z., Rey, S., Wei, H., Liu, J. O., \& Semenza, G. L. (2009). Anthracycline chemotherapy inhibits HIF-1 transcriptional activity and tumor-induced mobilization of circulating angiogenic cells. Proc Natl Acad Sci USA, 106, 2353-2358.

Lee, K. A., Lee, Y. J., Ban, J. O., Lee, Y. J., Lee, S. H., Cho, M. K., et al. (2012). The flavonoid resveratrol suppresses growth of human malignant pleural mesothelioma cells through direct inhibition of specificity protein 1. Int J Mol Med, 30, 21-27.

Lee, T. J., Jung, E. M., Lee, J. T., Kim, S., Park, J. W., Choi, K. S., et al. (2006). Mithramycin A sensitizes cancer cells to TRAIL-mediated apoptosis by down-regulation of XIAP gene promoter through Sp1 sites. Mol Cancer Ther, 5, 2737-2746.

Lee, W. R., Kim, K. H., An, H. J., Park, Y. Y., Kim, K. S., Lee, C. K., et al. (2013). Effects of chimeric decoy oligodeoxynucleotide in the regulation of transcription factors NF-kB and Sp1 in an animal model of atherosclerosis. Basic Clin Pharmacol Toxicol, 112, 236-243.

Lee, W. S., Kwon, J., Yun, D. H., Lee, Y. N., Woo, E. Y., Park, M. J., et al. (2014). Specificity protein 1 expression contributes to Bcl-w-induced aggressiveness in glioblastoma multiforme. Mol Cells 37, 17-23.

Lemon, B., \& Tjian, R. (2000). Orchestrated response: a symphony of transcription factors for gene control. Genes Dev, 14, 2551-2569. 
Leng, F., Priebe, W., \& Chaires, J. B. (1998). Ultratight DNA binding of a new bisintercalating anthracycline antibiotic. Biochemistry, 37, 1743-1753.

Letovsky, J., \& Dynan, W. S. (1989). Measurement of the binding of transcription factor Sp1 to a single GC box recognition sequence. Nucleic Acids Res, 17, 2639-2653.

Li, H., Zhang, Y., Strose, A., Tedesco, D., Gurova, K., \& Selivanova, G. (2014a). Integrated high-throughput analysis identifies Sp1 as a crucial determinant of p53-mediated apoptosis. Cell Death Differ, 21, 1493-1502.

Li, L., \& Davie, J. R. (2010). The role of Sp1 and Sp3 in normal and cancer cell biology. Ann Anat, 192, 275-283.

Li, L., Gao, P., Li, Y., Shen, Y., Xie, J., Sun, D., et al. (2014b). JMJD2A-dependent silencing of Sp1 in advanced breast cancer promotes metastasis by downregulation of DIRAS3. Breast Cancer Res Treat, 147, 487-500.

Li, L., He, S., Sun, J. M., \& Davie, J. R. (2004). Gene regulation by Sp1 and Sp3. Biochem Cell Biol, 82, 460-471.

López-Soto, A., Quiñones-Lombrana, A., López-Arbesu, R., López-Larrea, C., \& González, S. (2006). Transcriptional regulation of ULBP1, a human ligand of the NKG2D receptor. $J$ Biol Chem, 281, 30419-30430.

Lou, Z., O'Reilly, S., Liang, H., Maher, V. M., Sleight, S. D., \& McCormick, J. J. (2005). Downregulation of overexpressed $\mathrm{Sp} 1$ protein in human fibrosarcoma cell lines inhibits tumor formation. Cancer Res, 65, 1007-1017.

MacQuarrie, K. L., Fong, A. P., Morse, R. H., \& Tapscott, S. J. (2011). Genome-wide transcription factor binding: beyond direct target regulation. Trends Genet, 27, 141-148.

Majello, B., De Luca, P., Suske, G., \& Lania, L. (1995). Differential transcriptional regulation of c-myc promoter through the same DNA binding sites targeted by Sp1-like proteins. Oncogene, 10, 1841-1848. 
Malek, A., Núñez, L. E., Magistri, M., Brambilla, L., Jovic, S., Carbone, G. M., et al. (2012). Modulation of the activity of Sp transcription factors by mithramycin analogues as a new strategy for treatment of metastatic prostate cancer. PLoS ONE, 7, e35130.

Manne, U., Srivastava, R. G., \& Srivastava, S. (2005). Recent advances in biomarkers for cancer diagnosis and treatment. Drug Discov Today, 10, 965-976.

Mansilla, S., \& Portugal, J. (2008). Sp1 transcription factor as a target for anthracyclines: Effects on gene transcription. Biochimie, 90, 976-987.

Mansilla, S., Priebe, W., \& Portugal, J. (2004). Sp1-targeted inhibition of gene transcription by WP631 in transfected lymphocytes. Biochemistry, 43, 7584-7592.

Mansilla, S., Priebe, W., \& Portugal, J. (2006a). Mitotic catastrophe results in cell death by caspase-dependent and caspase-independent mechanisms. Cell Cycle, 5, 53-60.

Mansilla, S., Priebe, W., \& Portugal, J. (2006b). Transcriptional changes facilitate mitotic catastrophe in tumour cells that contain functional p53. Eur J Pharmacol, 540, 34-45.

Mansilla, S., Priebe, W., \& Portugal, J. (2011). Changes in gene expression induced by Sp1 knockdown differ from those caused by challenging Sp1 binding to gene promoters. Biochim Biophys Acta, 1809, 327-336.

Mansilla, S., Rojas, M., Bataller, M., Priebe, W., \& Portugal, J. (2007). Circumvention of the multidrug-resistance protein (MRP-1) by an antitumor drug through specific inhibition of gene transcription in breast tumor cells. Biochem Pharmacol, 73, 934-942.

Marin, M., Karis, A., Visser, P., Grosveld, F., \& Philipsen, S. (1997). Transcription factor Sp1 is essential for early embryonic development but dispensable for cell growth and differentiation. Cell, 89, 619-628.

Martín, B., Vaquero, A., Priebe, W., \& Portugal, J. (1999). Bisanthracycline WP631 inhibits basal and Sp1-activated transcription initiation in vitro. Nucleic Acids Res, 27, 3402-3409. 
Mertens-Talcott, S. U., Chintharlapalli, S., Li, X., \& Safe, S. (2007). The oncogenic microRNA27a targets genes that regulate specificity protein transcription factors and the G2-M checkpoint in MDA-MB-231 breast cancer cells. Cancer Res, 67, 11001-11011.

Minotti, G., Menna, P., Salvatorelli, E., Cairo, G., \& Gianni, L. (2004). Anthracyclines: molecular advances and pharmacologic developments in antitumor activity and cardiotoxicity. Pharmacol Rev, 56, 185-229.

Minuzzo, M., Marchini, S., Broggini, M., Faircloth, G., D'Incalci, M., \& Mantovani, R. (2000). Interference of transcriptional activation by the antineoplastic drug ecteinascidin-743. Proc Natl Acad Sci USA, 97, 6780-6784.

Miyata, K., Yotsumoto, F., Nam, S. O., Odawara, T., Manabe, S., Ishikawa, T., et al. (2014). Contribution of transcription factor, Sp1, to the promotion of HB-EGF expression in defense mechanism against the treatment of irinotecan in ovarian clear cell carcinoma. Cancer Med, 3, 1159-1169.

Mobahat, M., Narendran, A., \& Riabowol, K. (2014). Survivin as a preferential target for cancer therapy. Int J Mol Sci, 15, 2494-2516.

Moorefield, K. S., Yin, H., Nichols, T. D., Cathcart, C., Simmons, S. O., \& Horowitz, J. M. (2006). Sp2 localizes to subnuclear foci associated with the nuclear matrix. Mol Biol Cell, $17,1711-1722$.

Mottet, D., Pirotte, S., Lamour, V., Hagedorn, M., Javerzat, S., Bikfalvi, A., et al. (2009). HDAC4 represses p21(WAF1/Cip1) expression in human cancer cells through a Sp1dependent, p53-independent mechanism. Oncogene, 28, 243-256.

Nair, V., Pathi, S., Jutooru, I., Sreevalsan, S., Basha, R., Abdelrahim, M., et al. (2013). Metformin inhibits pancreatic cancer cell and tumor growth and downregulates Sp transcription factors. Carcinogenesis, 34, 2870-2879.

Nair, V., Sreevalsan, S., Basha, R., Abdelrahim, M., Abudayyeh, A., Rodrigues Hoffman, A., et al. (2014). Mechanism of metformin-dependent inhibition of mammalian target of 
rapamycin (mTOR) and Ras activity in pancreatic cancer: role of specificity protein (Sp) transcription factors. J Biol Chem, 289, 27692-27701.

Nicolás, M., Noé, V., \& Ciudad, C. J. (2003). Transcriptional regulation of the human Sp1 gene promoter by the specificity protein (Sp) family members nuclear factor Y (NF-Y) and E2F. Biochem J, 371, 265-275.

Nikulenkov, F., Spinnler, C., Li, H., Tonelli, C., Shi, Y., Turunen, M., et al. (2012). Insights into p53 transcriptional function via genome-wide chromatin occupancy and gene expression analysis. Cell Death Differ, 19, 1992-2002.

Noé, V., Alemany, C., Chasin, L. A., \& Ciudad, C. J. (1998). Retinoblastoma protein associates with $\mathrm{Sp} 1$ and activates the hamster dihydrofolate reductase promoter. Oncogene, 16, 1931-1938.

Noratto, G. D., Jutooru, I., Safe, S., Angel-Morales, G., \& Mertens-Talcott, S. U. (2013). The drug resistance suppression induced by curcuminoids in colon cancer SW-480 cells is mediated by reactive oxygen species-induced disruption of the microRNA-27a-ZBTB10Sp axis. Mol Nutr Food Res, 57, 1638-1648.

Núñez, L. E., Nybo, S. E., González-Sabín, J., Pérez, M., Menéndez, N., Braña, A. F., et al. (2012). A novel mithramycin analogue with high antitumor activity and less toxicity generated by combinatorial biosynthesis. J Med Chem, 55, 5813-5825.

O'Sullivan-Coyne, G., O'Sullivan, G. C., O'Donovan, T. R., Piwocka, K., \& McKenna, S. L. (2009). Curcumin induces apoptosis-independent death in oesophageal cancer cells. $\mathrm{Br} J$ Cancer, 101, 1585-1595.

Oeggerli, M., Tian, Y., Ruiz, C., Wijker, B., Sauter, G., Obermann, E., et al. (2012). Role of KCNMA1 in breast cancer. PLoS ONE, 7, e41664.

Papineni, S., Chintharlapalli, S., Abdelrahim, M., Lee, S. O., Burghardt, R., Abudayyeh, A., et al. (2009). Tolfenamic acid inhibits esophageal cancer through repression of specificity proteins and c-Met. Carcinogenesis, 30, 1193-1201. 
Park, J. H., McMillan, D. C., Horgan, P. G., \& Roxburgh, C. S. (2014). The impact of antiinflammatory agents on the outcome of patients with colorectal cancer. Cancer Treat Rev, $40,68-77$.

Pathi, S., Jutooru, I., Chadalapaka, G., Nair, V., Lee, S. O., \& Safe, S. (2012). Aspirin inhibits colon cancer cell and tumor growth and downregulates specificity protein ( $\mathrm{Sp}$ ) transcription factors. PLoS ONE, 7, e48208.

Piedrafita, F. J., \& Pfahl, M. (1997). Retinoid-induced apoptosis and Sp1 cleavage occur independently of transcription and require caspase activation. Mol Cell Biol, 17, 63486358.

Portugal, J., Mansilla, S., Vizcaíno, C., \& Barceló, F. (2011). Promoter-specific transcriptional interference by DNA-binding drugs. In Recent Research Developments in Biochemistry (Vol. 8, pp. 45-63). Kerala: Research Signpost.

Portugal, J., Martín, B., Vaquero, A., Ferrer, N., Villamarín, S., \& Priebe, W. (2001). Analysis of the effects of daunorubicin and WP631 on transcription. Curr Med Chem, 8, 1-8.

Previdi, S., Malek, A., Albertini, V., Riva, C., Capella, C., Broggini, M., et al. (2010). Inhibition of Sp1-dependent transcription and antitumor activity of the new aureolic acid analogues mithramycin SDK and SK in human ovarian cancer xenografts. Gynecol Oncol, 118, 182188.

Priebe, W., Fokt, I., Przewloka, T., Chaires, J. B., Portugal, J., \& Trent, J. O. (2001). Exploting anthracycline scaffold for designing DNA-targeting agents. Methods Enzymol, 340, 529555.

Pugh, B. F., \& Tjian, R. (1990). Mechanism of transcriptional activation by Sp1: Evidence for coactivators. Cell, 61, 1187-1197.

Roeder, R. G. (2003). The eukaryotic transcriptional machinery: complexities and mechanisms unforeseen. Nat Med, 9, 1239-1244. 
Safe, S., \& Abdelrahim, M. (2005). Sp transcription factor family and its role in cancer. Eur J Cancer 41, 2438-2448.

Safe, S., Imanirad, P., Sreevalsan, S., Nair, V., \& Jutooru, I. (2014). Transcription factor Sp1, also known as specificity protein 1 as a therapeutic target. Expert Opin Ther Targets, 18, 759769.

Saha, S., Mukherjee, S., Mazumdar, M., Manna, A., Khan, P., Adhikary, A., et al. (2015).

Mithramycin A sensitizes therapy-resistant breast cancer stem cells toward genotoxic drug doxorubicin. Transl Res, 165, 558-577.

Sankpal, U. T., Goodison, S., Abdelrahim, M., \& Basha, R. (2011). Targeting Sp1 transcription factors in prostate cancer therapy. Med Chem, 7, 518-525.

Sankpal, U. T., Lee, C. M., Connelly, S. F., Kayaleh, O., Eslin, D., Sutphin, R., et al. (2013). Cellular and organismal toxicity of the anti-cancer small molecule, tolfenamic acid: a preclinical evaluation. Cell Physiol Biochem, 32, 675-686.

Sankpal, U. T., Maliakal, P., Bose, D., Kayaleh, O., Buchholz, D., \& Basha, R. (2012).

Expression of specificity protein transcription factors in pancreatic cancer and their association in prognosis and therapy. Curr Med Chem, 19, 3779-3786.

Shaw, T. J., Lacasse, E. C., Durkin, J. P., \& Vanderhyden, B. C. (2008). Downregulation of XIAP expression in ovarian cancer cells induces cell death in vitro and in vivo. Int J Cancer, $122,1430-1034$.

Sherr, C. J., \& Roberts, J. M. (1999). CDK inhibitors: positive and negative regulators of G1phase progression. Genes Dev, 13, 1501-1512.

Siegel, R. L., Miller, K. D., \& Jemal, A. (2015). Cancer statistics, 2015. CA Cancer J Clin, 65, 529.

Sleiman, S. F., Langley, B. C., Basso, M., Berlin, J., Xia, L., Payappilly, J. B., et al. (2011). Mithramycin is a gene-selective Sp1 Inhibitor that identifies a biological intersection between cancer and neurodegeneration. J Neurosci, 31, 6858-6870. 
Snyder, R. C., Ray, R., Blume, S., \& Miller, D. M. (1991). Mithramycin blocks transcriptional initiation of the c-myc P1 and P2 promoters Biochemistry, 30, 4290-4297.

Sorianello, E., Soriano, F. X., Fernández-Pascual, S., Sancho, A., Naon, D., Vila-Caballer, M., et al. (2012). The promoter activity of human Mfn2 depends on Sp1 in vascular smooth muscle cells. Cardiovasc Res, 94, 38-47.

Sreevalsan, S., \& Safe, S. (2013). The cannabinoid WIN 55,212-2 decreases specificity protein transcription factors and the oncogenic cap protein eIF4E in colon cancer cells. Mol Cancer Ther, 12, 2483-2493.

Stevens, C., Smith, L., \& La Thangue, N. B. (2003). Chk2 activates E2F-1 in response to DNA damage. Nat Cell Biol, 5, 401-409.

Suske, G. (1999). The Sp-family of transcription factors. Gene, 238, 291-300.

Sutphin, R. M., Connelly, S. F., Lee, C. M., Sankpal, U. T., Eslin, D., Khan, M., et al. (2014). Anti-leukemic response of a NSAID, tolfenamic acid. Target Oncol, 9, 135-144.

Tapias, A., Ciudad, C. J., Roninson, I. B., \& Noé, V. (2008). Regulation of Sp1 by cell cycle related proteins. Cell Cycle, 7, 2856-2867.

Terrados, G., Finkernagel, F., Stielow, B., Sadic, D., Neubert, J., Herdt, O., et al. (2012). Genome-wide localization and expression profiling establish $\mathrm{Sp} 2$ as a sequence-specific transcription factor regulating vitally important genes. Nucleic Acids Res, 40, 7844-7857.

Tora, L., \& Timmers, H. T. (2010). The TATA box regulates TATA-binding protein (TBP) dynamics in vivo. Trends Biochem Sci, 35, 309-314.

Torre, L. A., Bray, F., Siegel, R. L., Ferlay, J., Lortet-Tieulent, J., \& Jemal, A. (2015). Global cancer statistics, 2012. CA Cancer J Clin, 65, 87-108.

Vaquero, A., \& Portugal, J. (1998). Modulation of DNA-protein interactions in the P1 and P2 cmyc promoters by two intercalating drugs. Eur J Biochem, 251, 435-442. 
Vizcaíno, C., Mansilla, S., Núñez, L. E., Méndez, C., Salas, J. A., Morís, F., et al. (2012). Novel mithramycins abrogate the involvement of protein factors in the transcription of cell cycle control genes. Biochem Pharmacol, 84, 1133-1142.

Vizcaíno, C., Nuñez, L. E., Morís, F., \& Portugal, J. (2014). Genome-wide modulation of gene transcription in ovarian carcinoma cells by a new mithramycin analogue. PLoS ONE, 9 , e104687.

Wang, B. S., Liu, Z., Sun, S. L., \& Zhao, Y. (2014). Identification of genes and candidate agents associated with pancreatic cancer. Tumour Biol, 35, 81-88.

Wang, L., Guan, X., Zhang, J., Jia, Z., Wei, D., Li, Q., et al. (2008a). Targeted inhibition of Sp1mediated transcription for antiangiogenic therapy of metastatic human gastric cancer in orthotopic nude mouse models. Int J Oncol, 33, 161-167.

Wang, L., Wei, D., Huang, S., Peng, Z., Le, X., Wu, T. T., et al. (2003). Transcription factor Sp1 expression is a significant predictor of survival in human gastric cancer. Clin Cancer Res, 9, 6371-6380.

Wang, X. B., Peng, W. Q., Yi, Z. J., Zhu, S. L., \& Gan, Q. H. (2007). [Expression and prognostic value of transcriptional factor sp1 in breast cancer]. Ai Zheng, 26, 996-1000.

Wang, Y. T., Chuang, J. Y., Shen, M. R., Yang, W. B., Chang, W. C., \& Hung, J. J. (2008b). Sumoylation of specificity protein 1 augments its degradation by changing the localization and increasing the specificity protein 1 proteolytic process. J Mol Biol, 380, 869-885.

Wierstra, I. (2008). Sp1: Emerging roles-Beyond constitutive activation of TATA-less housekeeping genes. Biochem Biophys Res Commun, 372, 1-13.

Wright, C., Angus, B., Napier, J., Wetherall, M., Udagawa, Y., Sainsbury, J. R., et al. (1987). Prognostic factors in breast cancer: immunohistochemical staining for SP1 and NCRC 11 related to survival, tumour epidermal growth factor receptor and oestrogen receptor status. J Pathol, 153, 325-331. 
Wu, J., Ling, X., Pan, D., Apontes, P., Song, L., Liang, P., et al. (2005). Molecular mechanism of inhibition of survivin transcription by the GC-rich sequence-selective DNA binding antitumor agent, hedamycin: evidence of survivin down-regulation associated with drug sensitivity. J Biol Chem, 280, 9745-9751.

Xu, Q., Liu, M., Xu, N., \& Zhu, H. (2014). Variation in Sp1 binding sites correlates with expression of survivin in breast cancer. Mol Med Rep, 10, 1395-1399.

Xu, R., Zhang, P., Huang, J., Ge, S., Lu, J., \& Qian, G. (2007). Sp1 and Sp3 regulate basal transcription of the survivin gene. Biochem Biophys Res Commun, 356, $286-292$.

Yan, C., \& Higgins, P. J. (2013). Drugging the undruggable: Transcription therapy for cancer. Biochim Biophys Acta, 1835, 76-85.

Yang, H. C., Chuang, J. Y., Jeng, W. Y., Liu, C. I., Wang, A. H., Lu, P. J., et al. (2014a). Pin1mediated Sp1 phosphorylation by CDK1 increases Sp1 stability and decreases its DNAbinding activity during mitosis. Nucleic Acids Res, 42, 13573-13587.

Yang, W. S., Chadalapaka, G., Cho, S. G., Lee, S. O., Jin, U. H., Jutooru, I., et al. (2014b). The transcriptional repressor ZBTB4 regulates EZH2 through a MicroRNA-ZBTB4-specificity protein signaling axis. Neoplasia, 16, 1059-1069.

Yao, J. C., Wang, L., Wei, D., Gong, W., Hassan, M., Wu, T. T., et al. (2004). Association between expression of transcription factor $\mathrm{Sp} 1$ and increased vascular endothelial growth factor expression, advanced stage, and poor survival in patients with resected gastric cancer. Clin Cancer Res, 10, 4109-4117.

Yu, B., Datta, P. K., \& Bagchi, S. (2003). Stability of the Sp3-DNA complex is promoterspecific: Sp3 efficiently competes with Sp1 for binding to promoters containing multiple Sp-sites. Nucleic Acids Res, 31, 5368-5376.

Yuan, P., Wang, L., Wei, D., Zhang, J., Jia, Z., Li, Q., et al. (2007). Therapeutic inhibition of Sp1 expression in growing tumors by mithramycin a correlates directly with potent antiangiogenic effects on human pancreatic cancer. Cancer, 110, 2682-2690. 
Zannetti, A., Del Vecchio, S., Carriero, M. V., Fonti, R., Franco, P., Botti, G., et al. (2000). Coordinate up-regulation of Sp1 DNA-binding activity and urokinase receptor expression in breast carcinoma. Cancer Res, 60, 1546-1551.

Zhang, J., Zhu, Z. G., Ji, J., Yuan, F., Yu, Y. Y., Liu, B. Y., et al. (2005). Transcription factor Sp1 expression in gastric cancer and its relationship to long-term prognosis. World $J$ Gastroenterol, 11, 2213-2217.

Zhang, J. P., Zhang, H., Wang, H. B., Li, Y. X., Liu, G. H., Xing, S., et al. (2014). Downregulation of Sp1 suppresses cell proliferation, clonogenicity and the expressions of stem cell markers in nasopharyngeal carcinoma. J Transl Med, 12, 222.

Zhang, M., Mathur, A., Zhang, Y., Xi, S., Atay, S., Hong, J. A., et al. (2012). Mithramycin represses basal and cigarette smoke-Induced expression of ABCG2 and inhibits stem cell signaling in lung and esophageal cancer cells. Cancer Res, 72, 4178-4192.

Zhang, Y., Sun, M., Shi, W., Yang, Q., Chen, C., Wang, Z., et al. (2015). Arsenic trioxide suppresses transcription of hTERT through down-regulation of multiple transcription factors in HL-60 leukemia cells. Toxicol Lett, 232, 481-489.

Zhao, C., \& Meng, A. (2005). Sp1-like transcription factors are regulators of embryonic development in vertebrates. Dev Growth Differ, 47, 201-211.

Zhao, S., Wu, J., Zheng, F., Tang, Q., Yang, L., Li, L., et al. (2015). $\beta$-elemene inhibited expression of DNA methyltransferase 1 through activation of ERK1/2 and AMPKalpha signalling pathways in human lung cancer cells: the role of Sp1. J Cell Mol Med, 19, 630641.

Zhao, Y., Zhang, W., Guo, Z., Ma, F., Wu, Y., Bai, Y., et al. (2013). Inhibition of the transcription factor Sp1 suppresses colon cancer stem cell growth and induces apoptosis in vitro and in nude mouse xenografts. Oncol Rep, 30, 1782-1792. 
Zhu, G. H., Lenzi, M., \& Schwartz, E. L. (2002). The Sp1 transcription factor contributes to the tumor necrosis factor-induced expression of the angiogenic factor thymidine phosphorylase in human colon carcinoma cells. Oncogene, 21, 8477-8485. 


\section{LEGENDS TO FIGURES}

Fig. 1. Schematic representation of transcriptional activation by Sp1. (A) A model for transactivation through co-activators, in which Sp1 binds to DNA and indirectly interacts with TBP (TATA-binding protein) and other general transcriptional factors (GTFs). (B) A model of Sp1 activation of a TATA-less promoter. Sp1 uses tethering co-factors to recruit TBP, which is likewise required for basal transcription from these promoters. Drugs that inhibit transcription can either compete with the different transcription factors and co-factors, including the members of the Sp-family, for binding to gene promoters or they can alter protein-protein interactions.

Fig. 2. Chemical structures of some molecules that decrease the expression of Sp1, Sp3 and Sp4 through a diversity of mechanisms or pathways. Doxorubicin, daunorubicin and actinomycin D bind to DNA by intercalation, and are well known antitumor drugs in clinical usage. WP631 bisintercalates into DNA with an affinity close to that of some transcription factors, and displaces Sp1 from binding to strong gene promoters. Curcumin, a natural compound extracted from plants, induces ROS and decreases $\mathrm{Sp}$ transcription factors by targeting microRNAs. Arsenic trioxide is also a ROS-inducing compound acting on Sp levels. Tolfenamic acid is a non-steroidal antiinflammatory drug that down-regulates Sp factors. See the main text for further details. Other relevant molecules are presented in Fig. 3.

Fig. 3. Chemical structures of mithramycin A and three of its analogues obtained by combinatorial biosynthesis. Mitharmycin A has been used in the clinical treatment of some tumors. The analogues differ in the composition of their 3'-site chain, while DIG-MSK also contains a different sugar in its trisaccharide moiety. All these molecules bind to DNA through its minor groove without intercalation. All mithramycins can displace Sp protein factors from their putative binding sites in promoters. In general the new analogues are less toxic and more effective 
against several tumor cell lines and xenografts in mice. See the main text for further details. Other relevant molecules are presented in Fig. 2.

Fig. 4. Gene Ontology (GO) categories containing genes that are significantly down-regulated in A2780 human ovarian cancer cells by the mithramycin analogue DIG-MSK ( $80 \mathrm{nM}$ final concentration). The GO analysis was performed online using PANTHER 7.0

(http://www.pantherdb.org). The genes down-regulated by the drug were retrieved from the Gene Expression Omnibus (GEO) database (Accession number: GSE46926). 

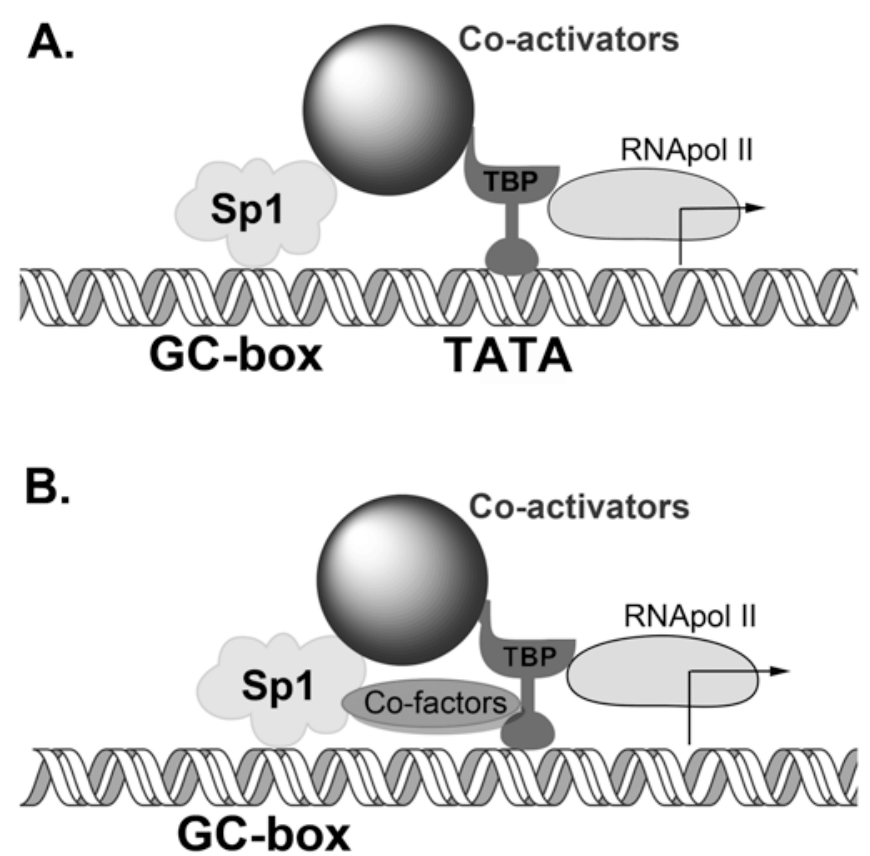

Figure 1 
<smiles>[R]C(=O)C1(O)Cc2c(O)c3c(c(O)c2C(OC2CC(N)C(O)C(C)O2)C1)C(=O)c1c(OC)cccc1C3=O</smiles><smiles>Cc1c2oc3c(C)ccc(C(=O)NC4C(=O)NC(C(C)C)C(=O)N5CCCC5C(=O)N(C)CC(=O)N(C)C(C(C)C)C(=O)OC4C)c3nc-2c(C(=O)NC2C(=O)NC(C(C)C)C(=O)N3CCCC3C(=O)N(C)CC(=O)N(C)C(C(C)C)C(=O)OC2C)c(N)c1=O</smiles>

Actinomycin D<smiles>COc1cc(/C=C/C(=O)CC(=O)/C=C/c2ccc(O)c(OC)c2)ccc1O</smiles><smiles>O=[As]O[As]=O</smiles>
Arsenic trioxide<smiles>COc1cccc2c1C(=O)c1c(O)c3c(c(O)c1C2=O)CC(O)(C(C)=O)CC3O</smiles><smiles>C=CC(=O)NCC1CC(OC2Cc3c(O)c4c(c(O)c3C2)C(=O)c2c(OC)cccc2C4=O)OC(O)(C(C)=O)C1</smiles><smiles>Cc1c(Cl)cccc1Nc1ccccc1C(=O)O</smiles>

Tolfenamic acid

Figure 2 

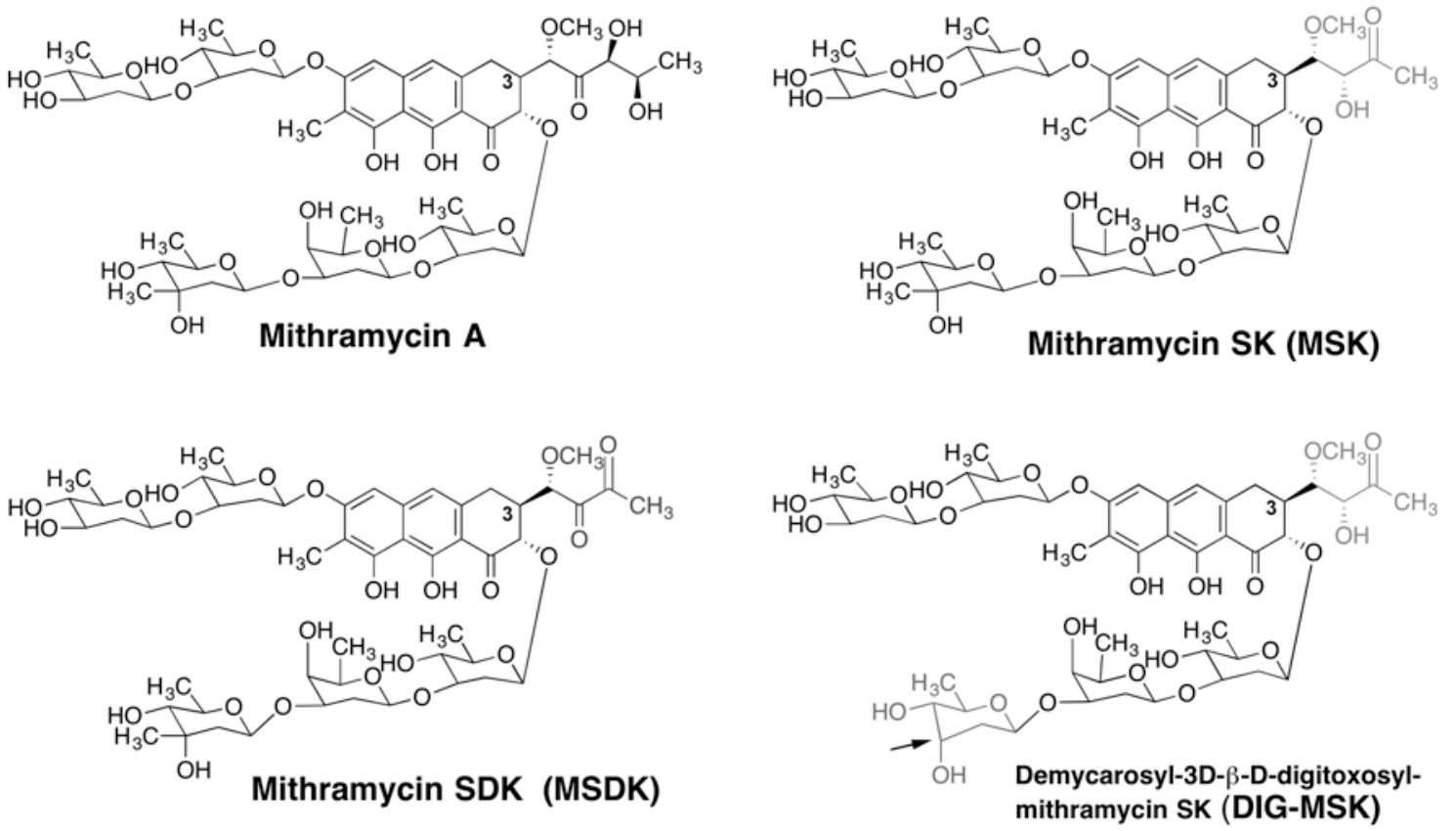

Figure 3 


\section{BIOLOGICAL PROCESS}

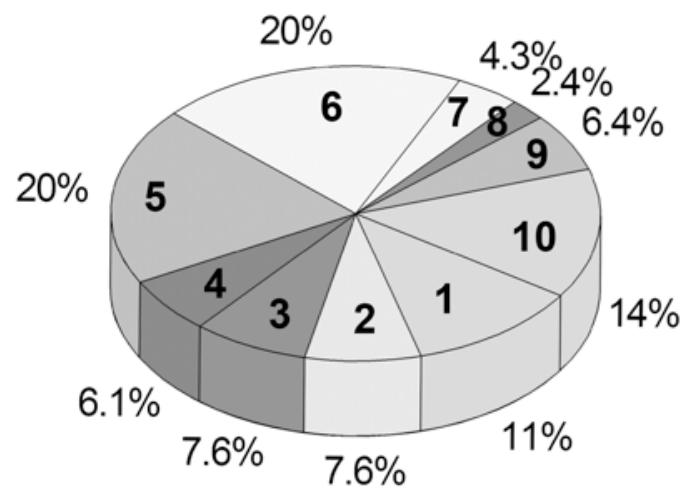

1. Nucleobase and nucleic acid process

2. Transcription

3. Transcription from pol II promoter

4. Regulation transcription from pol II promoter

5. Primary Metabolic process

6. Metabolic process

7. System development

8. Maintenance of chromatin architecture, and organelle organization

9. Developmental process

10. Cellular process

\section{MOLECULAR FUNCTION}

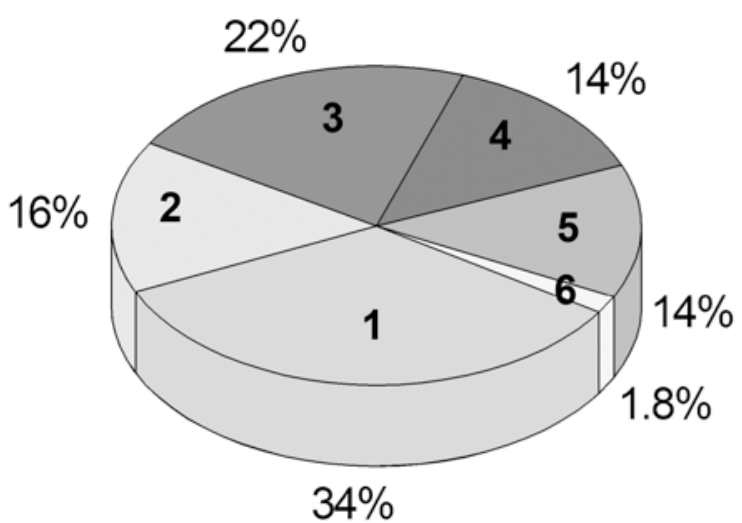

Figure 4
1. Binding

2. DNA binding

3. Nucleic acid binding

4. Transcription factor activity

5. Trancription regulator activity

6. Transcription cofactor activity, and structural components ribosome 